\title{
Investigating the Behaviour Change Techniques and Motivational Interviewing Techniques In Physical Activity Counselling Sessions
}

\author{
Jean-Christian Gagnon
}

Thesis submitted to the Faculty of Graduate and Postdoctoral Studies in partial fulfillment of the requirements for the degree of Master of Arts in Human Kinetics

\author{
Faculty of Health Sciences \\ School of Human Kinetics \\ University of Ottawa
}

(C) Jean-Christian Gagnon, Ottawa, Canada, 2017 


\section{ACKNOWLEDGEMENTS}

Michelle, merci de m'avoir accueilli dans ton lab, d'avoir investi de ton temps dans mon cheminement et d'avoir été un modèle exceptionnel de travail et de vie. Ta positivité, ton mindset et ta façon de faire briller les gens autour de toi sont sans doute quelques-unes de tes nombreuses qualités qui font travailler avec toi une vraie partie de plaisir. Ton désir de me voir m’épanouir dans les différentes sphères de ma vie fait de moi une personne extrêmement privilégiée et je suis tellement content d'avoir la chance de nourrir notre amitié/complicité dans les années à venir! Thanks to my committee members, Dr. Martin Camiré and Dr. Diane SteMarie, for providing me with constructive feedback and helping me grow as a graduate student and researcher. Your valuable time invested and interest shown in my research project is greatly appreciated! The last two years wouldn't have been as pleasurable without my lovely colleagues. First and foremost, I can't imagine having been paired with a better lab mate than you, Taylor. Thank you for being such a great example to follow, fun to work with, and for always being available to help even when you are extremely busy. You have a beautiful soul and I feel so lucky to have you as a friend! Yannick, such a gem! Merci d'avoir investi de ton temps et de ton énergie pour l'analyse des données - même si c'était long, nos fous rires en ont valu la peine! Mélanie, merci d'avoir rendu la transition à la maîtrise si « smooth ». Tes conseils de 'vétérante' et nos nombreuses discussions de musique franco ont rendu le processus agréable! Also, I would like to thank other faculty members (François, Brad, Julie) and student-colleagues (who you who you are) who had a positive impact in this journey. Maman, Papa, Éli, Papi \& Nanou, merci de croire en moi; faire partie d'une famille si unie est un catalyseur pour le succès autant au travail que dans les autres sphères de ma vie. Bonne lecture! :; 


\section{TABLE OF CONTENTS}

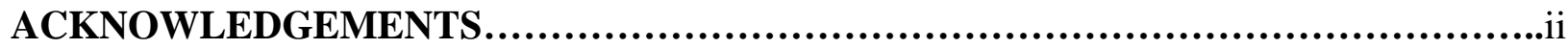

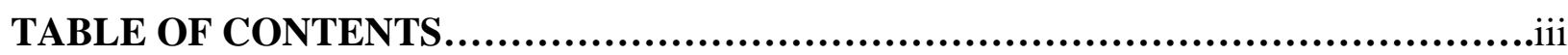

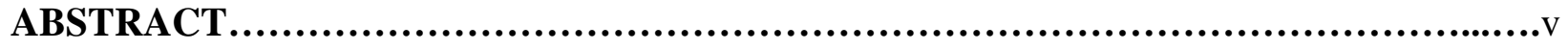

CHAPTER I: INTRODUCTION..............................................................1

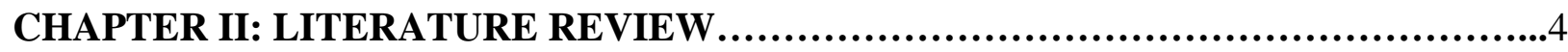

Physical Activity Interventions..................................................

Behaviour Change Techniques...................................................

Research on BCTs in the PA Context................................................

Quantity of BCTs and Intervention Effectiveness................................... 10

Motivational Interviewing: An Approach to Promote Health Behaviour Change...............11

Self-Determination Theory: An Explanatory Framework of MI............................ 12

The Role of Relational Style in Promoting Behaviour Change............................. 14

Table of Motivational Interviewing Techniques..................................... 15

Study Objectives........................................................... 17

Significance of Study ............................................................ 18

CHAPTER III: JOURNAL ARTICLE.............................................20

Investigating the behaviour change techniques and Motivational Interviewing techniques in Physical Activity Counselling sessions

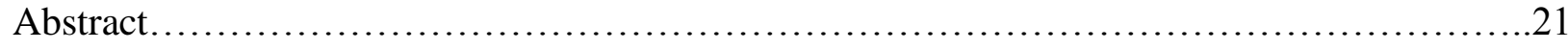

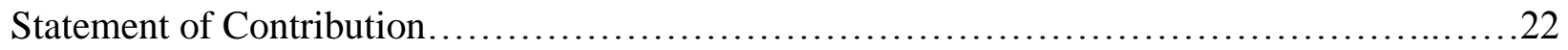

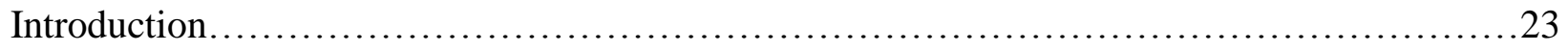

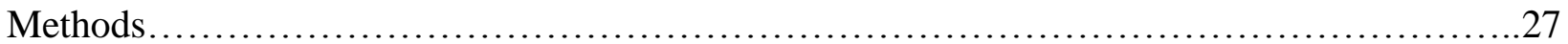


Results...................................................................... 30

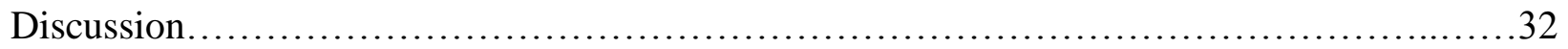

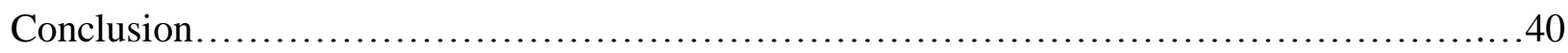

References...................................................................... 41

Appendix S1 - TIDieR Checklist.................................................52

Tables/Figures............................................................. 55

CHAPTER IV: GENERAL DISCUSSION ...............................................62

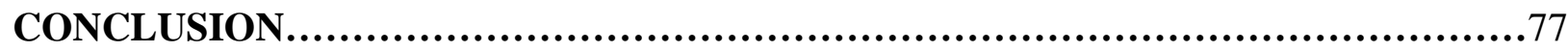

CONTRIBUTIONS OF THE AUTHORS...............................................79

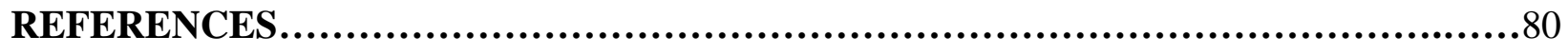

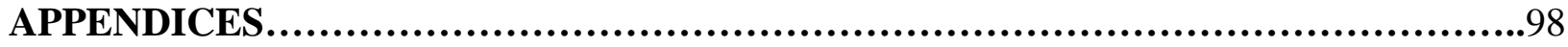

Appendix A - Definitions of Common Behaviour Change Techniques (BCTs)...............98

Appendix B - Motivational Interviewing Process Stages.............................. 102

Appendix C - Distinctiveness and Overlap of MI techniques and BCTs....................103

Appendix D - Table of MI techniques......................................... 104

Appendix E - Coding Framework for PAC sessions................................... 107

Appendix F - Motivational Interviewing Techniques and Basic Psychological Needs..........108 


\begin{abstract}
Background: In Canada, only $15 \%$ of adults meet the physical activity guidelines (Colley et al., 2011). As regular physical activity has been demonstrated to substantially improve physical and mental health (Naci \& Ioannidis, 2013; Schuch et al., 2016), a wealth of physical activity promoting interventions have been developed and evaluated (Kahn et al., 2002; Prince et al., 2014). Physical Activity Counselling (PAC) is one of these and has been shown effective in increasing physical activity motivation and behaviour (Fortier et al., 2011). However, the active ingredients of PAC have never been reported in detail, thus limiting our potential for understanding its effectiveness and to allow for its replication. Recently, taxonomies have been published for characterizing behaviour change techniques (BCTs) and Motivational Interviewing (MI) techniques in interventions (Hardcastle et al., 2017; Michie et al., 2013). Due to its novelty, no studies to date have used the MI technique taxonomy to report interventions.

Purpose: To investigate the behaviour change techniques (BCTs) and Motivational Interviewing (MI) techniques applied in PAC sessions delivered by student-counsellors.

Methods: PAC 1 and PAC 2 sessions delivered by 11 student-counsellors were double coded for identification of BCTs and MI techniques, for a total of 22 video recorded sessions. Two trained coders rated the presence of BCTs and MI techniques using the Behaviour Change Technique Taxonomy v1 (BCTTv1) and the table of MI techniques. Inter coder agreement was assessed using Cohen's kappa and the prevalence- and bias-adjusted kappa (PABAK) statistic.
\end{abstract}

Results: Overall, 29 BCTs (on 93) and 27 MI techniques (on 38) were reliably coded across the sampled PAC sessions (Cohen's $k=.81$, PABAK=.91). Popular BCTs included 3.1 Social support (unspecified), 1.1 Goal setting (behaviour), 1.4 Action planning, whereas OARS skills (i.e., open-ended questions, affirmations, reflective and summary statements) and 24. Emphasize 
autonomy were the predominating MI techniques. On average, 5.7 BCTs and 9.5 MI techniques were recorded per session.

Conclusions: Findings of this study provide a first detailed report of a PAC intervention and have important implications for PAC training and replication. Future research in this area specifically looking at the quality of application of the techniques and the influence of use and quality on physical activity behaviour over time is recommended. 


\section{CHAPTER I: INTRODUCTION}

Physical inactivity is the fourth leading risk factor of mortality worldwide (WHO, 2009) and is responsible for costs estimated at 10.0 billion dollars annually in Canada alone (Krueger $e t$ al., 2014). Physical inactivity is defined as a level of activity insufficient to meet the physical activity (PA) guidelines, which recommend a minimum of 150 minutes of moderate- to vigorous-intensity aerobic physical activity throughout the week, in bouts of 10 minutes or more (Tremblay et al., 2011). However, reports show that only 15\% of Canadian adults meet these guidelines, leaving an alarming $85 \%$ insufficiently active (Colley et al., 2011).

Regular physical activity (PA) is associated with a reduced risk of premature death and developing chronic illnesses such as cardiovascular disease, diabetes, cancer, hypertension and osteoporosis (Hoffmann et al., 2016; Naci \& Ioannidis, 2013). Moreover, PA has gained much attention over recent years for its psychological benefits. Indeed, research showed that people who engage in regular PA have higher rates of positive affect (Stanton, Happell, Hayman, \& Reaburn, 2014) and a reduced risk of depression (Mammen \& Faulkner, 2013; Parker et al., 2016; Schuch et al., 2016). As physical inactivity creates a significant economic burden on the health care system and contributes significantly to much of the mortality and morbidity around the world, numerous interventions directed at increasing physical activity levels have been developed and evaluated (Kahn et al., 2002; Malik, Blake \& Suggs, 2014; Prince, Saunders, Gresty, \& Reid, 2014).

One example of an intervention for increasing PA levels is Physical Activity Counselling (Fortier et al., 2007). Physical Activity Counselling (PAC) is directed at motivating individuals to increase their PA levels for their own reasons, through a Motivational Interviewing counselling style and the application of evidence-based behaviour change techniques (Fortier et 
al., 2007). Randomized controlled trials have been conducted and have shown a positive shortto mid-term effect of physical activity counselling on patients' motivation and PA levels and different health indicators (Bouchard, Baillargeon, Gagnon, Brown, \& Langlois, 2012; Fortier, Hogg et al., 2011; Gao et al., 2016). Accordingly, national public guidelines and health promotion agencies around the world have recommended the provision of PAC in primary care to increase the population's uptake of PA (Department of Health and Human Services, 2014; Exercise is Medicine, 2017; National Institute for Health and Care Excellence, 2013). However, the lack of knowledge and of confidence in providing PAC are barriers experienced internationally that constrain its implementation by health care providers (Bock, Diehm, \& Schneider, 2012; Patel, Schofield, Kolt, \& Keogh 2011; Petrella, Lattanzio, \& Overend, 2007).

While the effects of PAC have been demonstrated in previous studies (Fortier et al., 2011; Gao et al., 2016; McFadden, Fortier \& Guérin, 2017), the ingredients of the intervention have yet been reported. As is generally the case of behaviour change interventions, the poor description of PAC limits our ability to understand its effectiveness and facilitate its replication (Michie, Fixsen, Grimshaw, \& Eccles, 2009). For this reason, taxonomies of behaviour change techniques (Michie et al., 2013) and Motivational Interviewing techniques (Hardcastle, Fortier, Blake, \& Hagger, 2016) were developed to facilitate the detailed reporting of interventions and, in turn, cumulate evidence across the literature to better inform practice. Given its relative novelty, no studies have yet applied the table of MI techniques to report MI-based interventions.

The overarching purpose of this dissertation was to provide a detailed account of the techniques delivered in PAC 1 and 2 sessions ${ }^{1}$. The specific objectives were to: 1$)$ quantify the frequency of use of BCTs and MI techniques across PAC 1 and 2 sessions 2) quantify the

\footnotetext{
${ }^{1}$ PAC 1 session refers to the initial session with a client, whereas PAC 2 session refers to the second session with the same client.
} 
average number of BCTs and MI techniques applied in PAC 1 and 2 sessions and 3) quantify the frequency of using BCTs and MI techniques belonging to the $16 \mathrm{BCT}$ categories and the four MI process stages across a sample of PAC 1 and 2 sessions.

The following chapters of this dissertation will consist of the following: (II) Literature Review, (III) Empirical article to be submitted to The British Journal of Health Psychology, and (IV) General Discussion. Moreover, appendices defining the common BCTs and MI techniques reported are presented at the end of this dissertation to allow for a better understanding of the results. 


\section{CHAPTER II: LITERATURE REVIEW}

\section{Physical Activity Interventions}

Due to the epidemic of physical inactivity and its alarming consequences (Kohl et al., 2012; Lee et al., 2012), a wealth of PA promoting initiatives have been developed and evaluated over the last 20 years. A systematic review performed by Kahn et al (2002) provided an overview of informational, behavioural and social as well as environmental and policy approaches designed to increase PA along with information about their overall effectiveness. Among the various behavioural and social initiatives, individually-adapted health behaviour change interventions were proven effective in increasing PA behaviour (Kahn et al., 2002). Contrary to interventions targeting large groups of individuals using a one size fits all approach, individually-adapted behaviour change interventions can be tailored to an individual (Jepson, Harris, Platt, \& Tannahill, 2010). Such interventions often involve strengthening motivation of individuals and teaching them behavioural management skills to incorporate more PA into their daily routines (Marcus et al., 2006).

One example of such individually-adapted health behaviour change interventions is Physical Activity Counselling (PAC). Physical Activity Counselling is an individual, face-toface intervention that uses a Motivational Interviewing (MI) counselling style and behaviour change techniques to motivate individuals to become more physically active for their own reasons (Fortier et al., 2007). The intervention investigated in this dissertation is inspired by the Physical Activity Counselling trial, a randomized controlled trial evaluating the impact of integrating a PA counsellor in a primary care setting on patients' PA motivation and PA levels (Fortier et al., 2007). Findings from this trial suggested that PAC provided by physical activity specialists trained in MI and behaviour change was valuable in promoting changes in the 
quantity and quality of motivation as well as increasing PA levels (Fortier, Hogg et al., 2011; Fortier, Wiseman et al., 2011). Moreover, findings from a recent study examining the effects of a 2-month PAC intervention delivered to depressed female undergraduate students revealed increases in PA levels and decreases in depressive symptoms (McFadden et al., 2017).

Consistent with these findings, national public health agencies recommend counselling in regards to PA to address the widespread problem of physical inactivity (Department of Health and Human and Human Services, 2014; Exercise is Medicine, 2017; National Institute for Health and Care Excellence, 2013). Specifically, guidelines suggest tailoring PA interventions to the patient's goals and motivation, current level of activity and ability, circumstances, preferences and barriers to being physically active, and health status (National Institute for Health and Care Excellence, 2013). Despite these recommendations, health providers are faced with several challenges preventing them to counsel their patients on PA. According to a systematic review, the lack of knowledge/training in PA counselling and the lack of counselling protocols are among frequently reported barriers of PAC implementation in health care (Hébert, Caughy, \& Shuval, 2012).

While the effects of PAC have been investigated in previous research (Fortier, Hogg et al., 2011; Gao et al., 2016; McFadden et al., 2017), the content of PAC has never been described thoroughly. This leaves us with very little information regarding what exactly is delivered in the intervention and consequently limits the adoption and scaling up of PAC in health care. Therefore, providing a detailed description of PAC interventions is essential in order to being able to better understand its effectiveness and inform practice. 


\section{Behaviour Change Techniques}

Interventions aimed at changing health behaviours are typically complex and include many interacting components (Craig et al., 2008). The poor description and the inconsistent terminology across the literature to describe interventions have been identified as important issues limiting knowledge advancements and contributions to practice (Michie, Fixsen et al., 2009). Taken together, these factors significantly limit our understanding of the mechanisms through which interventions operate, and consequently hamper our ability to replicate effective interventions (Michie, Fixsen et al., 2009). Therefore, a call for a systematic method to specify the content and delivery of behaviour change interventions was made to accelerate knowledge advancements and inform the delivery of effective interventions (Michie, Fixsen et al., 2009).

In response to the aforementioned gaps, taxonomies of behaviour change techniques (BCTs) were developed in order to provide valid and standard methodological tools to report interventions. A behaviour change technique (BCT) is defined as an "observable, replicable, and irreducible component of an intervention designed to alter or redirect the causal processes that regulate behaviour" (Michie et al., 2013, p. 82). Abraham and Michie (2008) developed a 26item taxonomy of theory-linked BCTs, which was the first attempt at establishing a common method for specifying the content of behaviour change interventions. Following this pioneer work, methods have been developed to accurately specify the BCTs of smoking cessation (Lorencatto, West, Seymour, \& Michie, 2013; Michie, Hyder, Walia, \& West, 2011) and physical activity and healthy eating interventions Michie, Ashford et al., 2011). Finally, the Behaviour Change Technique version 1 (BCTTv1) is the most recent development in the area, and represents "the first consensus-based, cross-domain taxonomy of distinct BCTs to be published" (Michie et al., 2013, p. 89). 
The BCTTv1 comprises a total of 93 BCTs clustered into 16 categories. Under each, a list of BCTs sharing similar active ingredients by the mechanism of change is provided (Michie et al., 2013). Feedback and monitoring, Goals and planning, Social support, and Shaping knowledge are examples of BCT categories in the BCTTv1. For instance, BCTs grouped within Feedback and monitoring include feedback on behaviour, biofeedback, self-monitoring of behaviour, and self-monitoring of outcome(s) of behaviour. The BCTTv1 has been used and researched extensively (Cradock et al., 2017; Presseau et al., 2015), allowing the identification of effective BCTs for PA behaviour change. Please refer to Appendix A for the definition of the common BCTs discussed in this thesis.

\section{Research on BCTs in the PA Context}

A meta-regression of 122 behaviour change interventions promoting PA and healthy eating in adults was conducted to assess the overall effectiveness of the interventions, and to determine if specific BCTs are predictive of improved outcomes (Michie, Abraham, Whittington, McAteer, \& Gupta, 2009). The authors found an overall moderate effect for the included interventions, and concluded that those including the BCT of self-monitoring, in combination with at least one other self-regulation technique (e.g., goal setting) were associated with improved outcomes.

In a similar vein, Greaves et al (2011) performed a systematic review of reviews to examine intervention techniques associated with increased effectiveness of physical activity and dietary interventions in adults at risk of developing type 2 diabetes. Their findings were in line with those of the meta-regression by Michie, Abraham, et al (2009), as they revealed that selfregulation techniques (i.e., goal setting and self-monitoring) were associated with increased effectiveness in interventions targeting weight loss, dietary outcomes, change in PA, and 
combined outcomes. Additionally, interventions including a social support component lead to greater weight loss at long-term in comparison with interventions with no social support. With respect to PA behaviour initiation, results suggested that prompting practice, self-monitoring of behaviour, individual tailoring and goal setting were effective techniques whereas the use of time management techniques and encouraging self-talk was supported for promoting increased PA maintenance.

Other meta-analyses have investigated which BCTs are effective in changing PA selfefficacy and PA behaviour for healthy (Williams \& French, 2011) and overweight/obese individuals (Olander et al., 2013; Samdal, Eide, Barth, Williams, \& Meland, 2017). Selfefficacy, defined as one's conviction in his or her ability to perform the required course of action to attain a desired outcome, is the most influential cognitive mediator in studies looking into PA behaviour change (Trost, Owen, Bauman, Sallis, \& Brown, 2002; Lubans, Foster, \& Biddle, 2008). Williams and French (2011) found that action planning and provide instruction were associated with significantly higher levels of both PA self-efficacy and PA behaviour among healthy adults.

On the other hand, Olander et al (2013) found over 20 effective BCTs for changing obese individuals' PA. For instance, the BCTs prompt self-monitoring of behavioural outcome and plan social support/social change were effective in yielding positive changes in both PA selfefficacy and PA behaviour of obese individuals. Above all, interventions that included the BCTs of teach to use prompts/cues, prompt practice, and prompt rewards contingent on effort or progress toward behaviour were found to have the largest effects in terms of PA behaviour change (Olander et al., 2013). Samdal and colleagues' meta-analysis (2017) provided additional support for self-regulation techniques as the BCTs self-monitoring of behaviour and goal setting 
predicted the short- and long-term effects of the included PA and healthy eating interventions.

Furthermore, BCT effectiveness was assessed in two recent meta-analyses of interventions targeting individuals diagnosed with type 2 diabetes (Cradock et al., 2017; Hankonen et al., 2015). Goal setting, goal review, social support, action planning, selfmonitoring and preparing for setbacks were the primary BCTs that predicted weight loss and behaviour change (for both PA and diet) in people with recently diagnosed diabetes (Hankonen et al., 2015). Whereas in Cradock and colleagues' meta-analysis (2017), the BCTs instruction on how to perform a behaviour, behavioural practice/rehearsal, demonstration of the behaviour and action planning were associated with significant reductions in $\mathrm{HbA}_{1 \mathrm{c}}$, a widely measured biomarker for diabetes assessment and continuing treatment.

Overall, goal setting, action planning, self-monitoring, and behavioural practice seem to be cornerstone techniques to bring about PA behaviour change. Particularly, goal setting, action planning, and self-monitoring techniques point to the importance of self-regulation, a widely acclaimed theoretical model to explain behaviour change maintenance (Kwasnicka, Dombrowski, White, \& Sniehotta, 2016). Self-regulation can be defined as an iterative process whereby individuals use specific skills and strategies to modulate their thoughts, emotions and behaviours over time and context to persist in goal pursuit (Zimmerman, 1989). Zimmerman and Campillo (2003) have proposed a cyclical model of self-regulation including three distinct phases. The forethought phase precedes the performance of a given behaviour and involves setting a goal and creating a plan to attain this goal. Second is the performance phase, during which the individual implements the strategies while executing the behaviour. Self-reflection is the last phase of self-regulation, whereby the individual engages in self-evaluation after the performance of the behaviour. Goal setting is the catalyst of the self-regulation process and takes 
place during the forethought phase (Zimmerman, 2006). Once an intended action is specified, it can be further developed through action planning by specifying other modalities (e.g., frequency, intensity, context, duration, etc.) for its performance. Self-monitoring is an essential technique taking place in the performance and self-reflection phases as it allows perceiving discrepancies between actual and desired states, consequently leading individuals to adjust their efforts throughout goal pursuit (control theory - Carver \& Scheier, 1982). Taking this into consideration, the wide support given to these techniques highlight the importance of self-regulation in PA behaviour change.

\section{Quantity of BCTs and Intervention Effectiveness}

While the effectiveness of individual BCTs has been evaluated in PA behaviour change interventions, the total number of BCTs used has been found to have an impact on intervention effectiveness, and should therefore also be examined in future studies. Systematic reviews examining PA interventions for adults with type-2 diabetes showed that a higher number of BCTs used is associated with increased effectiveness (Avery, Flynn, Van Wersch, Sniehotta, \& Trenell, 2012; Cradock et al., 2017). This conclusion is supported by the findings of a recent study in which a higher number of BCTs was positively associated with a greater decrease in BMI after one year (Hankonen et al., 2015). Similarly, a systematic review and meta-analysis of internet-based health behaviour change interventions concluded that interventions using more BCTs tended to yield larger effects as opposed to those that incorporated fewer BCTs (Webb, Joseph, Yardley, \& Michie, 2010). As proposed by Webb et al (2010), the inclusion of a greater quantity of BCTs could facilitate behaviour change by targeting different aspects of the behaviour change process. Given that the total number of BCTs may be an important indicator of intervention effectiveness, the present study sought to determine the average quantity of BCTs 
applied in PAC.

\section{Motivational Interviewing: An Approach to Promote Health Behaviour Change}

While BCTs have gained significant attention in recent years, a complementary intervention approach to elicit behaviour change is Motivational Interviewing (MI). Motivational Interviewing is defined as “a collaborative conversation style for strengthening a person's own motivation and commitment to change" (Miller \& Rollnick, 2013, p. 12). This client-centered counselling style was inductively developed from clinical practice to help people with substance abuse and has been broadened to a variety of health behaviours (Miller \& Rollnick, 2013).

Motivational Interviewing differs from traditional advice-giving approaches and follows a fourstage process (Appendix B - Miller \& Rollnick, 2013).

The first stage, Engaging, is directed at creating a strong and trusting relational foundation between the counsellor and the client in order to promote an open discussion about change. The second stage, Focusing, aims to help the client find a clear and strategic direction toward a desired change (e.g., focusing on increasing PA levels). The third stage, Evoking, is where MI really distinguishes itself and focuses on resolving ambivalence by eliciting and reinforcing the client's own motivation to engage in the behaviour. The final stage of the MI process, Planning, involves taking concrete steps to develop a change plan and strengthen the client's commitment to it.

A wealth of evidence supports the effectiveness of MI interventions. A meta-analysis of 72 randomized controlled trials concluded that $\mathrm{MI}$ outperforms traditional advice-giving approaches in terms of behavioural and health-related outcomes in $80 \%$ of studies (Rubak, Sandbaek, Lauritzen, \& Christensen, 2005). Additionally, several randomized controlled trials and meta-analyses have proven the effectiveness of MI-based interventions in facilitating a 
number of health-related behaviours (Armstrong et al., 2011; Lundahl et al., 2013; Vanbuskirk \& Wetherell, 2014) including PA (Hardcastle, Taylor, Bailey, \& Castle, 2008; O’Halloran et al., 2014). Furthermore, findings of a recent meta-analysis revealed that client-centered interventions, such as MI, are associated with maintenance of PA and healthy eating behaviours over 12 months for overweight and obese adults (Samdal et al., 2017). Despite the popularity that MI has gained in changing behaviours, it has been criticized for lacking a theoretical framework from which we can understand its mechanisms (Teixeira, Palmeira, \& Vansteenkiste, 2012). Hence, efforts have been directed toward linking MI with Self-Determination Theory, as both approaches have strong similarities.

\section{Self-Determination Theory: Explanatory Framework of MI}

Self-Determination Theory (SDT) is an empirically supported theory of human motivation proposed by Deci and Ryan $(1985 ; 2010)$. The model presents a continuum comprising three types of motivation. Intrinsic motivation, the most self-determined type of motivation, reflects the engagement in a particular activity for the inherent satisfactions (e.g., enjoyment, interest, challenge, etc.) the activity brings (Ryan \& Deci, 2000). Alternatively, amotivation is represented by a lack of motivation (Ryan \& Deci, 2000). Extrinsic motivation refers to performing an activity because it is instrumental, in other words there is an external factor that is motivating oneself to perform the behaviour (Ryan \& Deci, 2000).

Motivation can be studied with regard to the extent to which a behaviour, such as PA, is self-determined. Generally speaking, a behaviour done willingly (i.e., volitional behaviour) is said to be self-determined, and non-self determined when it is externally controlled or done out of pressure (Ryan \& Deci, 2000). Organismic Integration Theory is a sub-theory of SDT presenting regulatory styles of motivation, which is particularly useful in disentangling extrinsic 
motivations (Ryan \& Deci, 2000). Indeed, four regulatory styles defined below allow differentiating extrinsically-motivated behaviours (Ryan \& Deci, 2000). External regulation is a non-self determined form of extrinsic motivation and refers to behaviours done for reward contingency or for meeting external demands. A less controlled regulatory style is introjected regulation, which involves ego-defensive (e.g., avoiding guilt or shame) or ego-enhancement (e.g., pride) processes. Alternatively, regulation through identification is a self-determined form of motivation by which the behaviour is recognized as personally relevant and is accepted by the individual. Finally, the most self-determined form of extrinsic motivation is integrated regulation, which develops when the individual consciously recognizes the congruence existing between the behaviour and his or her values and needs. Conclusions from recent systematic reviews revealed that self-determined PA motivation is a strong predictor of short and long-term participation in PA (Owen, Smith, Lubans, Ng, \& Lonsdale, 2014; Teixeira, Carraça, Markland, Silva, \& Ryan, 2012). Therefore, interventions should employ strategies that promote selfdetermined motivation.

Also central to SDT is the concept of the fundamental psychological needs of autonomy, competence, and relatedness (Deci \& Ryan, 2010). The need of autonomy reflects feelings of choice and that one is the instigator of one's own decisions (Ryan \& Deci, 2000). Second, a feeling of competence is achieved when one feels able to carry out a behaviour and feels effective in doing so (Ryan \& Deci, 2000). Finally, the need of relatedness is characterized as a sense of connectedness and belonging with others in the pursuit of a goal (Ryan \& Deci, 2000). Cognitive Evaluation Theory, a subtheory of SDT, suggests that individuals are more likely to experience self-determined motivation when their needs of autonomy, competence and relatedness are satisfied (Deci \& Ryan, 2010) and that social contexts that promote the needs will 
promote self-determined motivation and positive consequences.

Interestingly, experts recognized how MI provides a need-supportive context (Markland, Ryan, Tobin, \& Rollnick, 2005; Resnicow \& McMaster, 2012). For instance, MI supports autonomy by acknowledging a client's ability to generate strategies for behaviour change and by avoiding coercion. Assisting a client in developing appropriate goals and providing positive feedback are examples of how an MI counsellor can facilitate feelings of competence towards making a change. Finally, using an empathetic and non-judgmental communication style facilitates the need of relatedness.

Other similarities have been identified between MI and SDT. Namely, both models have motivation as the core concept, are person-centered, and emphasize the importance of autonomy and a positive emotional climate for optimal behaviour change (Deci \& Ryan, 2012; Miller \& Rollnick, 2012). Despite the fact that an SDT-MI marriage has not yet been formalized, SDT has been suggested as the optimal theoretical lens through which we can view MI interventions (Miller \& Rollnick, 2012). For example, a randomized controlled trial conducted by Fortier et al (2007) concluded that PAC delivered through a MI counselling style promotes PA behaviour change by fostering self-determined forms of PA motivation (Fortier, Wiseman et al., 2011).

\section{The Role of Relational Style in Promoting Behaviour Change}

As stated earlier, numerous systematic reviews and meta-analyses applied taxonomies of BCTs in order to determine effective BCTs in promoting PA. However, criticism has been raised in regards to the lack of attention given to the manner by which BCTs are presented (Hager \& Hardcastle, 2014). The BCTTv1 focuses on the content (i.e., content-based BCTs), and is silent on the relational techniques often present in interventions. This is an important limitation brought forward by BCTTv1 users having experienced a "lack of relevant techniques" while coding MI- 
and SDT-based interventions (Samdal et al., 2017, p. 11).

In their efforts towards building a theory of MI, Miller and Rose (2009) proposed that MI interventions comprise two active components: a relational component focused on empathy and the interpersonal 'spirit' (i.e., partnership, acceptance, compassion, and evocation), and a technical or content-based component aimed directly at eliciting client change talk. Experts have suggested that the relational style of MI involves a separate set of techniques that can interact with content-based techniques and affect behaviour change (Hagger \& Hardcastle, 2014). To support this, Moyers, Miller and Hendrickson (2005) examined 103 MI sessions of clients with substance abuse and found a positive association between therapist interpersonal skills and client involvement and cooperation. Given the emphasis that SDT/MI-based interventions place on creating an autonomy-supportive and a positive emotional climate for optimal behaviour change (Deci \& Ryan, 2012; Miller \& Rollnick, 2012), specifying relational techniques in addition to content-based techniques (i.e., BCTs) seems particularly relevant to report in behaviour change interventions. This was one of the purposes of this dissertation.

\section{Table of MI Techniques}

As it stands, MI is included in the BCTTv1, albeit represented very poorly. In fact, the only instance where MI is referred to is under the BCT 3.1 Social support (unspecified). This is problematic as MI is an intervention approach consisting of multiple techniques, rather than a single and irreducible BCT (Miller \& Rollnick, 2013). A potential reason for the poor attention given to MI in the BCTTv1 is that MI techniques were not clearly defined and isolated at the time the BCTTv1 was developed. Unfortunately, the lack of knowledge surrounding MI techniques limits our understanding of the effectiveness of MI-based interventions and our ability to replicate these interventions (Dobber et al., 2015; Hardcastle, 2014). 
Luckily, a recent conceptual review addressed these gaps by identifying the techniques of MI and aligning them with existing BCTs (Hardcastle et al., 2017). The authors conducted the review following a three-step process: 1) content analysis of Miller and Rollnick's MI book (2013), 2) testing identified MI techniques for independence and uniqueness, and 3) comparing MI techniques with BCTs in the BCTTv1. In total, $38 \mathrm{MI}$ techniques were identified and categorized according to the four MI process stages. The authors drew an important distinction by labeling each technique as content-based or relational. In fact, 16 out of the 38 identified MI techniques are labelled as relational, 14 of which are unique to MI and conceptually different from BCTs found in the BCTTv1. On the other hand, 14 of the $22 \mathrm{MI}$ content techniques are overlapping with BCTs included in the BCTTv1. Overall, 22 MI techniques are unique (i.e., nonoverlapping with BCTs from the BCTTv1), while the remaining 16 are regarded as conceptually equivalent to techniques found in the BCTTv1 (refer to Appendix C for a visual representation of BCT/MI distinctiveness). The complete table of MI techniques is presented in Appendix D.

Miller and Rollnick (2013) stressed that the counsellor's relational style is the foundation, and thus, paramount for effective MI interventions. Indeed, it has been recently recommended to specify the relational techniques in order to provide a complete and holistic picture of interventions (Hagger \& Hardcastle, 2014; Hardcastle et al., 2017).While the table of MI techniques is a great innovation in this regard, no studies have yet applied this tool to report the active ingredients of MI interventions. For this reason, this study relied on the table of MI techniques in addition to the commonly used BCTTv1 to investigate the content-based and relational ingredients in PAC 1 and 2 sessions. 


\section{Study Objectives}

Specifically, the main objectives of the present study were to:

1) Quantify the frequency of use of BCTs and MI techniques across a sample of PAC 1 and 2 sessions.

2) Quantify the average number of BCTs and MI techniques applied in PAC 1 and 2 sessions.

3) Quantify the frequency of using BCTs and MI techniques belonging to the 16 BCT categories and the four MI process stages across a sample of PAC 1 and 2 sessions.

For further exploration, comparisons were drawn between PAC 1 and PAC 2 sessions for each objective.

Preliminary objective. In accordance with guidelines for reporting interventions, a preliminary objective of the present study was to apply the Template for Intervention Description and Replication (TIDieR) checklist as a guiding framework to report the different components of PAC sessions in as much detail as possible.

Indeed, complete reporting of interventions facilitates their replication and implementation. In addition to reporting intervention techniques, researchers must describe other key intervention features (e.g., mode of delivery, duration, intensity, etc.) to ensure a thorough and exhaustive description (Hoffmann et al., 2014). While the creation of reporting guidelines such as the CONSORT (Consolidated Standards for Reporting Trials) 2010 and the SPIRIT (Standard Protocol Items: Recommendations for Interventional Trials) 2013 statements are helpful in addressing the issue of poor intervention description, intervention descriptions endorsing these guidelines remain deficient (Chan et al., 2013; Hoffmann et al., 2014; Schulz, Altman, Moher, \& Group, 2010). The Template for Intervention Description and Replication 
(TIDieR) consists of a 12-item checklist providing extensions to the CONSORT 2010 and SPIRIT 2013 statements, and aims to improve the reporting of interventions (Hoffmann et al., 2014).

\section{Significance of Study}

An area that has often been criticized in the literature is the poor description of interventions (Larkin et al., 2015; Michie, Fixsen et al., 2009). Transparency in the reporting of intervention content and delivery is "required to successfully evaluate, replicate and synthesise evidence from interventions" (Wood et al., 2015, p. 134). Thus, this study is aiming to fill this void by using the latest coding guidelines in order to provide a clearer description of the BCTs MI techniques applied in PAC sessions.

While previous research has investigated the effects of PAC on physical activity levels and mental health (Fortier, Hogg et al., 2011; McFadden, et al., 2017), none has provided a thorough account of the ingredients found in PAC. This is the first study to specify the BCTs and MI techniques found in PAC sessions using an internationally validated taxonomy of BCTs and the first conceptual list of MI techniques to report the content and relational ingredients of a PAC intervention (refer to Appendix E for coding framework). This study is particularly novel as no other study has yet applied Hardcastle et al's taxonomy (2017) to investigate the techniques applied in MI interventions.

Furthermore, this study elucidates the quantity of BCTs and MI techniques applied within sessions as well as the different aspects of the behaviour change process targeted in the intervention. In light of these objectives, this study offers a strong basis on which future research could rely on when reporting interventions. Such enhanced reporting will, in turn, allow the examination of which ingredients lead to better outcomes and facilitate the replication of 
effective interventions. Lastly, this study provides insightful information that can help train health professionals so they can optimally assist people in adopting and maintaining PA. 
CHAPTER III: JOURNAL ARTICLE

Running head: Describing Physical Activity Counselling sessions

\section{Investigating the behaviour change techniques and Motivational Interviewing techniques in Physical Activity Counselling sessions}

Jean-Christian Gagnon* ${ }^{* 1}$, Michelle Fortier ${ }^{1}$, Taylor McFadden ${ }^{1}$ and Yannick Plante ${ }^{1}$

${ }^{1}$ School of Human Kinetics, University of Ottawa

Word count (exc. figures/tables): 4979 


\begin{abstract}
Background. The positive effects of Physical Activity Counselling (PAC) on physical activity motivation, physical activity behaviour, and mental health have been shown. However, the ingredients included in PAC interventions have never been documented, thus preventing its replication. Moreover, no studies have used the new taxonomy of Motivational Interviewing (MI) techniques.
\end{abstract}

Objectives. The overarching purpose was to provide a detailed account of the content and the relational style in PAC sessions. The specific objectives were to 1) quantify the frequency of use of behaviour change techniques (BCTs) and MI techniques 2) quantify the average number of BCTs and MI techniques and 3) quantify the frequency of using BCTs and MI techniques belonging to BCT categories and MI process stages.

Design. A descriptive observational research design was used.

Methods. Twenty-two videotaped PAC sessions delivered by student-counsellors were double coded. The Behaviour Change Technique Taxonomy v1 and the table of MI techniques were applied to rate the presence of BCTs and MI techniques in PAC sessions.

Results. Overall, 29 BCTs and 27 MI techniques were reliably identified across the sample $(\mathrm{PABAK}=.91)$, with an average of 5.7 BCTs and 9.5 MI techniques documented per session. The BCT categories of Goals and planning and Social support were emphasized, whereas the Engaging and Evoking techniques of MI predominated in the analysis.

Conclusions. This study provides the first detailed report of common BCTs and MI techniques present in PAC sessions. Findings are particularly relevant to health providers and PAC trainers and future directions are offered. 


\section{Statement of Contribution}

\section{What is already known on this subject?}

- Behaviour change and Motivational Interviewing taxonomies exist for reporting interventions.

- Physical Activity Counselling (PAC) is a promising intervention to increase PA motivation and behaviour.

- While the effectiveness of PAC has been evaluated in the past, the content and relational style of PAC interventions has not been reported thus far.

\section{What does this study add?}

- First study to provide a detailed description of PAC ingredients.

- First study to document the techniques of an intervention using the table of MI techniques.

- First research to code both relational and content techniques. 


\section{Introduction}

According to the World Health Organization (WHO, 2009), physical inactivity ranks fourth as a leading risk factor of mortality worldwide, and is responsible for exorbitant annual costs approximating 10 billion dollars in Canada alone (Krueger, Turner, Krueger, \& Ready, 2014). On the other hand, regular physical activity has shown to be as effective as pharmacological interventions in the secondary prevention of non-communicable illnesses such as cardiovascular disease and diabetes (Naci \& Ioannidis, 2013). In addition to the physical health benefits of being active, physical activity offers many psychological benefits, such as reducing the risk of depression (Mammen \& Faulkner, 2013; Parker et al., 2016; Schuch et al., 2016), the leading cause of disability worldwide (WHO, 2017). The evidence stressing the importance of an active lifestyle is unequivocal; yet, an estimated $85 \%$ of Canadians are not meeting the current physical activity guidelines ${ }^{1}$ (Colley et al., 2011).

In order to address these alarming statistics, national guidelines recommend physical activity counselling to support patients in increasing the time they spend being active (Department of Health and Human and Human Services, 2014; Exercise is Medicine, 2017; National Institute for Health and Care Excellence, 2013). Physical Activity Counselling (PAC) provided by Kinesiologists with expertise in behavioural counselling has been identified as a promising intervention to support physical activity behaviour change (Bouchard, Baillargeon, Gagnon, Brown, \& Langlois, 2012; Fortier et al., 2011; Moore, Lee, Milligan, \& Giangregorio, 2015). This individual, face-to-face intervention aims to elicit a client's own motivation to become more physically active through a Motivational Interviewing counselling style and the use of behaviour change techniques (Fortier et al., 2007). However, like many other behaviour

\footnotetext{
${ }^{1}$ To obtain health benefits, adults aged 18-64 years should accumulate at least 150 minutes of moderate to vigorous intensity aerobic physical activity (MVPA) per week, in bouts of 10 minutes or more.
} 
change interventions, the ingredients of PAC remain unclear, making replication difficult (Michie, Fixsen, Grimshaw, \& Eccles, 2009). Indeed, a systematic review reported the lack of counselling protocols as one of the principal barriers faced by health professionals to counselling patients on physical activity (Hébert, Caughy, \& Shuval, 2012). Therefore, providing a faithful description of PAC is essential to being able to better understand its effectiveness and guide its implementation.

Recently, a team of international experts developed a cross-domain taxonomy of 93 behaviour change techniques to provide a common language to specify the content of interventions (BCTTv1; Michie et al., 2013). A behaviour change technique (BCT) is defined as an "observable, replicable, and irreducible component of an intervention designed to alter or redirect the causal processes that regulate behaviour" (Michie et al., 2013). The BCTTv1 consists of a comprehensive list of well-defined BCTs along with examples of how they can be applied in practice. The BCTs in the taxonomy are grouped in 16 categories, each corresponding to a mechanism of change through which the underlying BCTs exert their effect (e.g., Goals and planning). Self-regulation techniques (e.g., goal-setting, self-monitoring) have been repeatedly associated with increased physical activity in several systematic reviews and meta-analyses (Greaves et al., 2011; Samdal, Eide, Barth, Williams, \& Meland, 2017).

In addition to using self-regulatory BCTs, interventions adopting a person-centered counselling style, such as Motivational Interviewing, are associated with physical activity maintenance (Samdal et al., 2017). Unlike traditional advice-giving approaches, MI is a style of counselling directed at resolving ambivalence by eliciting the client's own motivation to make a positive change (Miller \& Rollnick, 2013). Interventions based on MI are complex and comprise multiple techniques to support behaviour change through a four-stage process (Miller \& 
Rollnick, 2013; Hardcastle, Fortier, Blake, \& Hagger, 2017). The first stage, Engaging, is directed at creating a strong counsellor-client relational alliance to promote an open discussion about change. Focusing is about finding a clear and strategic direction toward a desired change. Third is the Evoking stage, aimed at resolving ambivalence by eliciting and reinforcing the client's own motivation to engage in a behaviour. Finally, the Planning stage consists of developing a change plan and strengthening the client's commitment to it.

Numerous meta-analyses support the effectiveness of MI interventions in changing a number of health behaviours (Armstrong et al., 2011; Lundahl, Kunz, Brownell, Tollefson, \& Burke, 2013, VanBuskirk \& Wetherell, 2014), including physical activity (O’Halloran et al., 2014). Surprisingly, MI is referred to only once in the BCTTv1 under the BCT 3.1 Social support (unspecified) (Michie et al., 2013). This poor representation of MI is due to MI being categorized as a single, irreducible BCT, when in fact, it includes multiple techniques (Hardcastle et al., 2017). Another possible explanation is that techniques specific to MI were not isolated and classified at the time the BCTTv1 was developed (Hardcastle et al., 2017). Fortunately, a recent conceptual review addressed this issue by identifying the techniques of MI and aligning them with BCTs (Hardcastle et al., 2017). A total of $38 \mathrm{MI}$ techniques were detected. Of these, 22 are unique to MI while the remaining 16 are conceptually equivalent to some techniques in the BCTTv1 (Hardcastle et al., 2017).

The table of MI techniques proposed by Hardcastle and colleagues (2017) also draws an important distinction between content-based and relational techniques. Content-based techniques (e.g., identify past successes, troubleshooting) are designed to change behaviour directly (Hardcastle et al., 2017). In contrast, relational techniques (e.g., reflective statements, permission to provide information and advice) inform the interpersonal style through which the content- 
based techniques are delivered (Hardcastle et al., 2017). As the interpersonal style of the counsellor is paramount to the effectiveness of MI (Miller \& Rollnick, 2013; O'Halloran et al., 2014), the elucidation of the relational techniques used, in addition to the content-based techniques, is recommended to provide a more holistic description of interventions (Hagger \& Hardcastle, 2014; Hardcastle et al., 2017; Samdal et al., 2017).

While research efforts have been made to characterize and assess the effectiveness of behaviour change interventions based on the presence of BCTs (Cradock et al., 2017; Samdal et al., 2017), the relational style of delivery remains overlooked. It is important to acknowledge that research on BCTs is often based on in-text descriptions rather than objective observation of the intervention under study, which can increase the risk of reporting bias. The present study sought to address these gaps.

\section{The Present Study}

The overall aim of this study was to provide a detailed description of PAC 1 and PAC 2 sessions $^{2}$ through observation of video recordings. Specifically the objectives were to 1) quantify the frequency of using BCTs and MI techniques across a sample of PAC 1 and 2 sessions, 2) quantify the average number of BCTs and MI techniques applied in PAC 1 and 2 sessions and 3) quantify the frequency of using BCTs and MI techniques belonging to the $16 \mathrm{BCT}$ categories and the 4 MI process stages across a sample of PAC 1 and 2 sessions. For each of the stated objectives, comparisons between PAC 1 and 2 sessions were also drawn for further exploration. Guided by these objectives, this study provides an in-depth analysis of the mechanisms of change targeted by counsellors at different time points in the intervention.

\footnotetext{
${ }^{2}$ PAC 1 session refers to the initial session with a client, whereas PAC 2 session refers to the second session with the same client.
} 


\section{Methods}

The study obtained approval from the University of $X$ 's Research Ethics Board.

\section{Sample}

A total of 22 video recorded PAC sessions delivered by student-counsellors were double coded for identification of BCTs and MI techniques. Physical activity counsellors in this study were upper-year undergraduate students on the path of becoming Registered Kinesiologists who have received training in MI and behaviour change through the fourth year Physical Activity Counselling course offered at the University of $X$. The training also included bi-weekly laboratory sessions to allow students practicing techniques with their peers. The recorded PAC sessions were sampled purposively by the Professor and the Teaching Assistant to include the sessions delivered by top-ranked students. Specifically, PAC 1 and 2 sessions delivered by the 11 highest ranked student-counsellors who gave permission to use their video recordings were included in the analysis. The sample size was somewhat larger than that used in similar studies of physical activity ( $\mathrm{n}=18$ interviews; Smith, Taylor, \& Lavender, 2015) and smoking cessation ( $\mathrm{n}=15$ transcripts; Gainforth, Lorencatto, Erickson, West, \& Michie, 2016) interventions.

\section{Intervention}

As stated earlier, PAC aims to motivate individuals to become more physically active for their own reasons, through a MI counselling style and the application of BCTs. As part of the final assignment for the course, students were required to provide two individual, face-to-face PAC sessions (i.e., PAC 1 and 2 sessions at a two to four week interval) of approximately 30 to 60 minutes each. The client had to be outside of the student-counsellor's immediate social circle (e.g., friend of a friend) and express being insufficiently active (i.e., less than 150 minutes MVPA per week) as well as ambivalent towards increasing physical activity levels. The PAC 
sessions occurred at a time and location of convenience for the clients and lasted on average 49 minutes each $(M=48.8$ minutes, $S D=14.6$ minutes $)$. The completed Template for Intervention Description and Replication (TIDieR) checklist is presented in Appendix S1 to provide a detailed overview of the PAC 1 and 2 sessions.

\section{Procedures}

\section{Coding of BCTs and MI techniques}

The BCTTv1 (Michie et al., 2013) and the table of MI techniques (Hardcastle et al., 2017) were used to assess the presence and absence of BCTs and MI techniques applied during PAC sessions. The coders rated the presence and absence of techniques within each PAC session following a dichotomous scale, " 1 " signalling the presence, and " 0 ", the absence of a technique.

\section{Coder training}

Two graduate students who completed the Physical Activity Counselling course in prior years underwent training to analyze the sampled sessions. The coders first read through the BCTTv1 and the table of MI techniques several times to become familiar with the labels, definitions and examples for each technique. They subsequently completed the BCTTv1 online training, consisting of an interactive and self-directed resource that provides training for new users of the taxonomy. The training comprised six tutorial modules with quizzes and two assessments allowing trainees to receive immediate feedback on progress. As no coding manual for MI techniques has yet been established, the coders agreed to follow the BCTTv1 general coding principles (available on the training website) when identifying MI techniques in order to ensure homogeneity in reporting. The training was done in a single week and required approximately 25-30 hours of work from each coder (i.e., familiarization with BCTTv1 and table of MI techniques, BCTTv1 online training, intensive discussions between coders). 


\section{Pilot tests}

The coders performed three rounds of pilot analysis to practice identifying BCTs and MI techniques in PAC sessions. Each round of piloting consisted of analyzing independently the PAC 1 and 2 sessions of a student-counsellor, who was not part of the purposive sample. Disagreements were resolved through discussion following each session coded and clarifications were added to the coding framework to promote good reliability for the remaining sessions to be coded.

\section{Analysis}

Objective 1: Quantify the frequency of using BCTs and MI techniques in PAC sessions

Coders analyzed PAC 1 and 2 sessions delivered by the 11 student-counsellors for a total of 22 PAC sessions. Consistent with recent studies reporting BCTs (Gainforth et al., 2016; Cradock et al., 2017), the prevalence- and bias-adjusted kappa statistic (i.e., PABAK; Byrt, Bishop, \& Carlin, 1993) was assessed as an additional inter-rater reliability estimate to the Cohen's kappa to adjust for the high prevalence of negative agreement (i.e., when both coders agree that techniques are not present). Reliably coded BCTs and MI techniques (i.e., techniques identified by both coders) with information about their frequency of use were recorded for PAC 1, PAC 2 and all 22 PAC sessions.

\section{Objective 2: Quantify the average number of BCTs and MI techniques in PAC sessions}

The average number and the range of BCTs and MI techniques reliably coded per session were reported. Paired-sample t-tests $(\alpha=0.05)$ were also conducted to determine if significant differences in the quantity of BCTs and MI techniques applied between PAC 1 and 2 sessions existed. 
Objective 3: Quantify the frequency of using BCTs and MI techniques belonging to specific BCT categories and MI process stages

The frequency of using techniques belonging to specific BCT categories and MI process stages was obtained by totalling the number of BCTs and MI techniques used across PAC 1 and 2 sessions for each BCT category and MI process stage, respectively.

\section{Results}

Objective 1: Quantify the frequency of using BCTs and MI techniques in PAC sessions

Average inter-rater reliability measures for the presence and absence of techniques determined by Cohen's kappa and PABAK were .81 and .91 respectively, indicating very good agreement between coders (Altman, 1991).

The identified BCTs and their frequency of use across the PAC sessions are presented in Table 1. Overall, 29 BCTs out of a possible 93 (31.2\%) were reliably coded across the 22 PAC sessions. The BCTs applied most frequently were: 3.1 Social support (unspecified) (coded 100\% in PAC 1, 100\% in PAC 2), 1.1 Goal setting (behaviour) (55\% in PAC 1, $73 \%$ in PAC 2), 8.1 Behavioural practice/rehearsal (0\% in PAC 1, 91\% in PAC 2), 1.2 Problem solving (9\% in PAC 1, 64\% in PAC 2), and 1.4 Action planning (18\% in PAC 1, 55\% in PAC 2).

On the other hand, a total of $27 \mathrm{MI}$ techniques out of a possible $38(71.1 \%)$ were reliably coded across the 22 PAC sessions (Table 2). Relational MI techniques predominated in the analysis and included the following: 3. Reflective statements (100\% in PAC 1, 100\% in PAC 2), 24. Emphasize autonomy (100\% in PAC 1, $91 \%$ in PAC 2), 1. Open-ended questions (91\% in PAC 1, 91\% in PAC 2), 2. Affirmation (82\% in PAC 1, 91\% in PAC 2), and 4. Summary 
statements (73\% in PAC 1, 91\% in PAC 2). Other relational techniques applied by the studentcounsellors were 7. Permission to provide information and advice, 35. Support change/persistence; and 6. Review a typical day, and 8. Elicit-provide-elicit. Though less widespread than relational techniques, the most documented MI content techniques included: 11 . Confidence ruler, 21. Values exploration, 30. Normalizing, 15. Hypothetical thinking, and 17. Identify past successes.

\section{INSERT TABLES $1 \& 2$}

Objective 2: Quantify the average number of BCTs and MI techniques in PAC sessions

On average, a greater number of BCTs were reported in PAC $2(M=6.6, S D=3.0)$ compared to PAC $1(M=4.9, S D=1.4)$ sessions, though not reaching statistical significance, $t$ $(10)=1.618, p=.137$. In contrast, results suggest that a greater number of MI techniques were used in PAC $1(M=10.5, S D=1.1)$ compared to PAC $2(M=8.5, S D=3.0)$ sessions, with a difference approaching statistical significance, $t(10)=2.141, p=.058$. The number of BCTs used in a single PAC session ranged from 3 to 12 and the number of MI techniques ranged from 4 to 15 (Table 3). Overall, a greater variety of BCTs was observed throughout PAC 2 sessions (n =23) compared to PAC 1 sessions $(n=17)$, while there was no difference in the number of different MI techniques between PAC $1(n=22)$ and PAC $2(n=22)$ subsamples (Tables 1 and 2). 
Objective 3: Quantify the frequency of using BCTs and MI techniques belonging to specific BCT categories and MI process stages

Figure 1 and 2 depict the BCTs and MI techniques applied by student-counsellors according to the BCT categories and MI process stages, respectively. As shown in Figure 1, at least one BCT was identified in 14 out of the 16 BCT categories, while no BCT was reported within the Scheduled consequences (14) and Covert learning (16) categories. Behaviour change techniques pertaining to Goals and planning (1) and Social support (3) were predominant both in PAC 1 and 2 sessions. As it relates to MI, Figure 2 shows that all four process stages were targeted in PAC sessions, with an emphasis on Engaging and Evoking techniques. PAC 1 sessions had a much greater emphasis on Focusing and Planning techniques in comparison with PAC 2 sessions. Alternatively, the frequency of reporting techniques pertaining to the Engaging and Evoking stages were similar between the PAC 1 and PAC 2 subsamples.

\section{INSERT FIGURES $1 \& 2$}

\section{Discussion}

By using an internationally validated taxonomy of BCTs and the first conceptual list of MI techniques, this study provided a detailed account of content-based and relational techniques used within PAC sessions, which have, thus far, not been reported in the literature. To our knowledge, this is also the first study to specify the relational techniques in addition to the content-based BCTs across all health behaviour change interventions reported in this area.

Overall our findings suggest that PAC includes the delivery of multiple BCTs and MI techniques to promote physical activity motivation and behaviour change. With regards to the 
frequency of behaviour change techniques, nearly one third of the total number of BCTs was reliably coded in the analysis. Behaviour change techniques under the categories Social support (3) and Goals and planning (1) were particularly targeted both in PAC 1 and 2 sessions. The BCT 3.1 Social support (unspecified) was coded in each of the 22 PAC sessions analyzed, which is not surprising, as it directly refers to MI. Despite the fact that MI goes far beyond the provision of mere social support, creating a partnership is indeed a vital aspect of MI interventions such as PAC (Miller \& Rollnick, 2013).

Within the Goals and planning category, the BCTs 1.1 Goal setting (behaviour), 1.2 Problem solving and 1.4 Action planning predominated in the analysis, particularly in PAC 2 sessions. These findings are promising, as these BCTs in particular have been suggested to be most effective in supporting physical activity (Hankonen et al., 2015; Michie, Abraham, Whittington, \& McAteer, 2009). This was also confirmed in a review conducted by Rhodes and Pfaeflli (2010), which found self-regulation constructs to be the most influential mediators for PA behaviour change.

In line with theoretical explanations for behavioural maintenance (Kwasnicka, Dombrowski, White, \& Sniehotta, 2016; Maes \& Karoly, 2005), findings from recent metaanalyses suggest that action planning supplemented with coping planning (i.e., problem solving) is important in facilitating physical activity behaviour (Bélanger-Gravel, Godin, \& Amireault, 2013; Carraro \& Gaudreau, 2013). Problem solving or coping planning, which involves generating strategies to overcome potential barriers during goal pursuit, is warranted once an initial action plan has been developed (Michie et al., 2011). It is therefore logical that studentcounsellors in this study prompted problem solving later in the PAC intervention (i.e., 7 out of the 8 codes in PAC 2 sessions), after an initial action plan had been established. 
With respect to the frequency of MI techniques, our findings suggest that there is value in specifying MI techniques in addition to commonly reported BCTs, as 18 of the 27 reliably coded MI techniques were non-overlapping with BCTs in the BCTTv1. These techniques would have been missed if relying solely on the BCTTv1. A great variety of relational and content-based MI techniques were observed in the analysis, particularly those within the Evoking and Engaging stages. From a relational standpoint, 1. Open-ended questions, 2. Affirmations, 3. Reflective statements and 4. Summary statements, also known as 'OARS' techniques, were applied frequently across the PAC sessions. OARS techniques, albeit not directed at changing behaviour directly, are primary Engaging techniques characterizing the counselling style of MI (Miller \& Rollnick, 2013). Hence, this provides support that the student-counsellors respected the communication style of MI in their PAC sessions.

Moreover, student-counsellors tried to instill a sense of autonomy in their clients' behaviour change process by recognizing their ability for choice (24. Emphasize autonomy). Congruent with Cognitive Evaluation Theory (Deci \& Ryan, 2010), facilitating an individual's need for autonomy is suggested to contribute to increased self-determined motivation, which has been associated with physical activity maintenance (Teixeira, Carraça, Markland, Silva, \& Ryan, 2012). The student-counsellors created an autonomy-supportive climate in different ways, namely by eliciting the clients' own reasons for change, having them choose their physical activity goals and prompting them to generate solutions to overcome personally relevant barriers.

Several content-based MI techniques were utilized consistently across the sessions, including 21. Values exploration and 11. Confidence ruler. Many of the student-counsellors conducted values interviews, which entails exploring the client's values and discussing how physical activity fits in (or not) with these aspirations (Hardcastle et al., 2017; Miller \& Rollnick, 
2013). This technique fosters integrated regulation, whereby the individual feels congruency between one's behaviour and one's values and aspirations (Ryan \& Deci, 2000). This is promising as integrated regulation is consistently and positively associated with physical activity adoption and maintenance (Owen, Smith, Lubans, Ng, \& Lonsdale, 2014; Teixeira et al., 2012).

On the other hand, the MI technique 11. Confidence ruler was distributed more equally between PAC 1 and 2 sessions. By asking clients to rate their confidence in making a change in their physical activity on a 1-10 scale, the student-counsellors helped their client become more self-aware in regards to their belief in their ability to achieve the change they aspired to. Through the application of this technique, student-counsellors also aimed to elicit client change talk (i.e., arguments in favour of change) and support their client's self-efficacy through the use of followup questions (e.g., Why are you at a 6 and not a 3?).

Although a great variety of BCTs and MI techniques were identified in the PAC sessions, some techniques appeared to be underutilized. Perhaps the most disconcerting was our finding that the BCT 2.3 Self-monitoring of behaviour was applied only twice within the entire sample of PAC sessions. Undeniably, self-monitoring is one of the most effective BCTs to support shortand long-term physical activity behaviour change (Greaves et al., 2011; Michie, Abraham et al., 2009; Samdal et al., 2017). Behavioural monitoring is a crucial self-regulatory sub-process, enabling people to recognize the discrepancy between their current behaviour and the goals they set out for themselves (Carver \& Scheier, 1982). Thus, it is surprising that self-monitoring was absent from the majority of the PAC sessions as developing and amplifying discrepancy is central in MI as it can act as a powerful instigator of change (Kanfer \& Gaelick-Buys, 1991; Miller \& Rollnick, 2013). A possible explanation for its relative absence is that studentcounsellors might have lacked self-monitoring tools (e.g., physical activity logs, pedometers, 
etc.) to provide their client with during the sessions.

Another underutilized technique in the PAC sessions was asking the client to reflect on the positive and negative aspects of a given behaviour (BCT: 9.2 Pros and cons, MI technique: 9. Running head start). This is unfortunate as this technique can be impactful for developing discrepancy and resolving ambivalence (Miller \& Rollnick, 2013). In light of these caveats, our findings show that there remains room for improvement in the delivery of effective PAC sessions. These results are particularly relevant to those providing PAC training as incorporating the aforementioned techniques could potentially lead to the delivery of more effective PAC sessions.

Moving to objective 2, PAC sessions included on average 5.7 BCTs. This is consistent with results of a meta-regression that reported a mean quantity of 6.0 BCTs across a variety of physical activity and healthy eating interventions (Michie, Abraham et al., 2009). This suggests that PAC sessions, even when delivered by less experienced counsellors, are comparable to other physical activity promoting interventions in terms of the variety of BCTs utilized. From a practical standpoint, including a greater variety of BCTs in PAC sessions is recommended, to a certain extent, as previous research found a positive association between the quantity of BCTs and the effectiveness of health behaviour change interventions (Avery, Flynn, van Wersch, Sniehotta, \& Trenell, 2012; Hankonen et al., 2015; Webb, Joseph, Yardley, \& Michie, 2010). Overall, the quantity of MI techniques (9.5 MI techniques) was greater than that of BCTs in PAC sessions. Two explanations for this might be that the PAC training offered to the studentcounsellors in this study was primarily based on MI, and/or that the table of MI techniques considers both content-based and relational techniques, whereas the BCTTv1 focuses on intervention content and is silent on relational techniques. 
Although no statistically significant differences were found, BCTs tended to be more prevalent in PAC 2 sessions, while the opposite was observed for MI techniques. These trends suggest that certain MI techniques may lend themselves better to a first session (e.g., 6. Review a typical day, 17. Identify past successes and 21. Values exploration), where building a collaborative alliance with the client and resolving ambivalence through evocation of change talk are warranted (Crits-Christoph et al., 2011; Miller \& Rollnick, 2013). As the intervention unfolds, the focus of the conversation transitions into more tangible techniques to facilitate the engagement in physical activity (e.g., 1.2 Problem solving, 1.4 Action planning, 8.1 Behavioural practice/rehearsal, etc.), which might explain why there was a greater focus on BCTs in PAC 2 sessions (Miller \& Rollnick, 2013).

\section{Strengths}

There were several notable strengths associated with the present study. First, the Template for Intervention Delivery and Replication (TIDieR; Hoffmann et al., 2014) checklist was applied to ensure a high quality description of the intervention. This is in line with recent recommendations highlighted by behaviour change experts in order to improve the completeness of reporting and ultimately aid in replication of effective interventions (Hoffmann et al., 2014; Samdal et al., 2017).

Also, the presence of BCTs and MI techniques was determined through observation of videotaped PAC sessions rather than from a simple text description. This approach enables the objective verification of intervention delivery and reduces the risk of bias in reporting (Borrelli, 2011). Finally, our study yielded very good agreement between coders, suggesting that researchers could take note of the protocol adopted in this study to promote good reliability in future ones. 
Most importantly, this is the first study to use the table of MI techniques (Hardcastle et $a l ., 2017)$, which allows for the observation of relational style techniques in PAC sessions as well as MI content techniques. Finally, it is the first to report both BCTs and MI techniques to provide a thorough description of PAC. Undoubtedly, specifying the relational and content-based techniques applied in PAC is essential if we hope to better understand the factors that contribute to its effectiveness and to allow for its replication.

\section{Limitations and Future Directions}

Despite these strengths, this study comes with limitations that should be considered in future research. First, student-counsellors in the study were in the same cohort and were trained in a specific way, consequently producing a biased sample. Moreover, while the physical activity counsellors received high quality training from an $\mathrm{MI}$ and behaviour change expert, and they were selectively chosen as the top ranked students, their limited experience could have influenced the results. Future research should examine how the delivery of PAC provided by experienced Kinesiologists differs from what was found in this study.

To continue, the study investigated the BCTs and MI techniques utilized in PAC 1 and 2 sessions exclusively. In a recent study investigating the effects of a 2-month PAC intervention, it was reported that clients received 6.2 sessions on average during the intervention period (McFadden, Fortier, \& Guérin, 2017). This goes to show that the results of this study do not reflect the complete scope of PAC. Therefore, there was a greater potential for the application of techniques directed at creating a relational foundation with the client (i.e., MI relational techniques) and supporting physical activity initiation, as opposed to techniques targeting physical activity maintenance. In order to gain a better understanding of the full spectrum of techniques applied through PAC, future research should investigate the BCTs and MI techniques 
utilized from the beginning to the end of the intervention.

Finally, the PAC intervention was reported solely based on the presence and absence of BCTs and MI techniques. Our findings must be interpreted cautiously as they do not speak to the effectiveness of BCTs and MI techniques in increasing physical activity behaviour. Also, determining the presence of techniques is insufficient to make conclusions about the behaviour change potential of interventions, because techniques are not effective under all conditions (Chatzisarantis \& Hagger, 2007; Direito et al., 2014). Indeed, other factors speaking to the quality of delivering techniques (e.g., degree of enthusiasm, time spent on each technique, sequencing), should be examined as they may have an impact on the effectiveness of individual techniques. Future research should examine interventions like PAC as a dynamic system, taking into account both provider-delivered techniques and the clients' verbal statements and receipt of these techniques (Gainforth et al., 2016). Subsequently, effectiveness of PAC should be examined.

\section{Practical Applications}

Despite these limitations, practical applications are worthy of mention. First, our results provide initial guidance on the BCTs and MI techniques that health professionals can utilize when counselling patients on physical activity. For instance, Goals and planning BCTS and Engaging and Evoking MI techniques seem to lend themselves well to PAC. Second, this study will aid in the replication of PAC 1 and 2 sessions. Finally, Kinesiology departments providing PAC-related courses should take note of the study's findings, in addition to the evidence on effective BCTs for increased physical activity, as it may give indications about which BCTs and MI techniques would benefit from more attention in training (e.g., self-monitoring). 


\section{Conclusion}

Overall, results from this study suggest that PAC incorporates numerous BCTs and MI techniques to support physical activity behaviour change. Well established BCTs for physical activity, such as goal setting, were applied consistently in the 22 PAC sessions analyzed. Further, MI relational and content techniques were investigated, allowing to report the PAC intervention in greater depth. These findings are exploratory and future research is recommended to address the reported limitations to guide the implementation and replication of effective PAC interventions. 


\section{References}

Adriaanse, M. A., Vinkers, C. D., De Ridder, D. T., Hox, J. J., \& De Wit, J. B. (2011). Do implementation intentions help to eat a healthy diet? A systematic review and meta-analysis of the empirical evidence. Appetite, 56(1), 183-193. doi: 10.1016/j.appet.2010.10.012

Altman, D. G. (1991). Inter-rater agreement. Practical statistics for medical research, 5, 403409.

Armstrong, M. J., Mottershead, T. A., Ronksley, P. E., Sigal, R. J., Campbell, T. S., \& Hemmelgarn, B. R. (2011). Motivational interviewing to improve weight loss in overweight and/or obese patients: A systematic review and meta-analysis of randomized controlled trials. Obesity Reviews, 12(9), 709-723. doi:10.1111/j.1467789X.2011.00892.x

Avery, L., Flynn, D., Van Wersch, A., Sniehotta, F. F., \& Trenell, M. I. (2012). Changing physical activity behavior in type 2 diabetes. Diabetes Care, 35(12), 2681-2689. doi:10.2337/dc11-2452

Bélanger-Gravel, A., Godin, G., \& Amireault, S. (2013). A meta-analytic review of the effect of implementation intentions on physical activity. Health Psychology Review, 7(1), 23-54. doi:10.1080/17437199.2011.560095

Borrelli, B. (2011). The assessment, monitoring, and enhancement of treatment fidelity in public health clinical trials. Journal of Public Health Dentistry, 71(1), 52-63.

doi:10.1111/j.1752-7325.2011.00233.x 
Bouchard, D. R., Baillargeon, J. P., Gagnon, C., Brown, C., \& Langlois, M. F. (2012). Impact of health professionals' contact frequency on response to a lifestyle intervention with individuals at high risk for diabetes. Diabetes Research and Clinical Practice, 96(2), 129-134. doi:10.1016/j.diabres.2011.12.019

Byrt, T., Bishop, J., \& Carlin, J. B. (1993). Bias, prevalence and kappa. Journal of Clinical Epidemiology, 46(5), 423-429.

Carraro, N., \& Gaudreau, P. (2013). Spontaneous and experimentally induced action planning and coping planning for physical activity: A meta-analysis. Psychology of Sport and Exercise, 14(2), 228-248. doi:10.1016/j.psychsport.2012.10.004

Carver, C. S., \& Scheier, M. F. (1982). Control theory: A useful conceptual framework for personality - social, clinical, and health psychology. Psychological Bulletin, 92, 111-135. doi:10.1037/0033-2909.92.1.111

Chatzisarantis, N. L., \& Hagger, M. S. (2007). Mindfulness and the intention-behavior relationship within the theory of planned behavior. Personality and Social Psychology Bulletin, 33(5), 663-676. doi:10.1177/0146167206297401

Colley, R. C., Garriguet, D., Janssen, I., Craig, C. L., Clarke, J., \& Tremblay, M. S. (2011). Physical activity of Canadian adults: Accelerometer results from the 2007 to 2009 Canadian Health Measures Survey. Health Reports, 22(1), 7-14. doi:10.1016/j.yspm.2011.03.006 
Cradock, K. A., ÓLaighin, G., Finucane, F. M., Gainforth, H. L., Quinlan, L. R., \& Ginis, K. A. M. (2017). Behaviour change techniques targeting both diet and physical activity in type 2 diabetes: A systematic review and meta-analysis. International Journal of Behavioral Nutrition and Physical Activity, 14(1), 18. doi:10.1186/s12966-016-0436-0

Crits-Christoph, P., Gibbons, M. B. C., Hamilton, J., Ring-Kurtz, S., \& Gallop, R. (2011). The dependability of alliance assessments: The alliance-outcome correlation is larger than you might think. Journal of Consulting and Clinical Psychology, 79(3), 267-278. doi:10.1037/a0023668

Deci, E. L., \& Ryan, R. M. (2010). Self-Determination. In Corsini Encyclopedia of Psychology. doi:10.1002/9780470479216.corpsy0834

Department of Health and Human Services. (2014). Healthy People 2020. U.S. Department of Health and Human Services. Washington, D.C.: U.S Dept. of Health and Human Services. Retrieved at: https://www.healthypeople.gov/2020/topicsobjectives/topic/physical-activity/objectives

Direito, A., Dale, L. P., Shields, E., Dobson, R., Whittaker, R., \& Maddison, R. (2014). Do physical activity and dietary smartphone applications incorporate evidence-based behaviour change techniques? BMC Public Health, 14(1), 646. doi:10.1186/1471-2458$14-646$

Dobber, J., van Meijel, B., Barkhof, E., op Reimer, W. S., Latour, C., Peters, R., \& Linszen, D. (2015). Selecting an optimal instrument to identify active ingredients of the motivational interviewing-process. Journal of Psychosomatic Research, 78(3), 268-276. doi: 10.1016/j.jpsychores.2014.10.010

Exercise is Medicine. (2017). Retrieved at: http://www.exerciseismedicine.org/canada/ 
Fortier, M. S., Hogg, W., O’Sullivan, T. L., Blanchard, C., Reid, R. D., \& Sigal, R. D., ... \& Beaulac, J. (2007). The physical activity counselling (PAC) randomized controlled trial: rationale, methods, and interventions. Applied Phsyiology, Nutrition, and Metabolism, 32(6), 1170-1185. doi:10.1139/H07-075

Fortier, M. S., Hogg, W., O’Sullivan, T. L., Blanchard, C., Sigal, R. J., Reid, R. D., ... \& Culver, D. (2011). Impact of integrating a physical activity counsellor into the primary health care team: physical activity and health outcomes of the Physical Activity Counselling randomized controlled trial. Applied Physiology, Nutrition, and Metabolism, 36(4), 503514. doi:10.1139/h11-040

Gainforth, H. L., Lorencatto, F., Erickson, K., West, R., \& Michie, S. (2016). Characterizing clients' verbal statements in behavioural support interventions: The case of smoking cessation. British Journal of Health Psychology, 21(3), 600-612. doi:10.1111/bjhp.12188

Greaves, C. J., Sheppard, K. E., Abraham, C., Hardeman, W., Roden, M., Evans, P. H., \& Schwarz, P. (2011). Systematic review of reviews of intervention components associated with increased effectiveness in dietary and physical activity interventions. BMC Public Health, 11(1), 119. doi:10.1186/1471-2458-11-119

Hagger, M. S., \& Hardcastle, S. J. (2014). Interpersonal style should be included in taxonomies of behavior change techniques. Frontiers in Psychology, 5, 254. doi:10.3389/fpsyg.2014.00254

Hankonen, N., Sutton, S., Prevost, A. T., Simmons, R. K., Griffin, S. J., Kinmonth, A. L., \& Hardeman, W. (2015). Which behavior change techniques are associated with changes in physical activity, diet and body mass index in people with recently diagnosed diabetes?. Annals of Behavioral Medicine, 49(1), 7-17. doi:10.1007/s12160-014-9624-9 
Hardcastle, S. J. (2016). Commentary: Interpersonal style should be included in taxonomies of behavior change techniques. Frontiers in Psychology, 7, 894. doi:

10.3389/fpsyg.2016.00894

Hardcastle, S. J., Fortier, M., Blake, N., \& Hagger, M. S. (2017). Identifying content-based and relational techniques to change behavior in motivational interviewing. Health Psychology Review, 11(1), 1-16. doi:10.1080/17437199.2016.1190659

Hébert, E. T., Caughy, M. O., \& Shuval, K. (2012). Primary care providers' perceptions of physical activity counselling in a clinical setting: A systematic review. British Journal of Sports Medicine, 46(9), 625-631. doi:10.1136/bjsports-2011-090734

Hoffmann, T. C., Glasziou, P. P., Boutron, I., Milne, R., Perera, R., Moher, D., ... Michie, S. (2014). Better reporting of interventions: template for intervention description and replication (TIDieR) checklist and guide. BMJ, 348, 1687. doi:10.1136/bmj.g1687

Howlett, N., Trivedi, D., Troop, N. A., \& Chater, A. M. (2015). What are the most effective behaviour change techniques to promote physical activity and/or reduce sedentary behaviour in inactive adults? A systematic review protocol. BMJ Open, 5(8). doi: 10.1136/bmjopen-2015-008573

Josefsson, T., Lindwall, M., \& Archer, T. (2014). Physical exercise intervention in depressive disorders: Meta-analysis and systematic review. Scandinavian Journal of Medicine \& Science in Sports, 24(2), 259-272. 
Kanfer, F. H., \& Gaelick-Buys. (1991). Self-management methods. In F. H. Kanfer \& A. P. Goldstein (Eds.), Helping people change: A textbook of methods (pp. 305-360). New York: Pergamon Press.

Krueger, H., Turner, D., Krueger, J., \& Ready, A. E. (2014). The economic benefits of risk factor reduction in Canada: tobacco smoking, excess weight and physical inactivity. Canadian Journal of Public Health, 105(1), 69-78.

Kwasnicka, D., Dombrowski, S., White, M., \& Sniehotta, F. (2016). Theoretical explanations for maintenance of behaviour change: A systematic review of behaviour theories. Health Psychology Review, 10(3), 277-293. doi:10.1080/17437199.2016.1151372

Lara, J., Evans, E. H., O’Brien, N., Moynihan, P. J., Meyer, T. D., Adamson, A. J., ... \& Mathers, J. C. (2014). Association of behaviour change techniques with effectiveness of dietary interventions among adults of retirement age: a systematic review and meta-analysis of randomised controlled trials. BMC medicine, 12(1), 177. doi: 10.1186/s12916-014-0177-3

Lundahl, B., Moleni, T., Burke, B. L., Butters, R., Tollefson, D., Butler, C., \& Rollnick, S. (2013). Motivational interviewing in medical care settings: A systematic review and meta-analysis of randomized controlled trials. Patient Education and Counseling, 93(2), 157-168. doi:10.1016/j.pec.2013.07.012

Maes, S., \& Karoly, P. (2005). Self-Regulation assessment and intervention in physical health and illness: A review. Applied Psychology, 54(2), 267-299. doi:10.1111/j.14640597.2005.00210.x 
Mammen, G., \& Faulkner, G. (2013). Physical activity and the prevention of depression: A systematic review of prospective studies. American Journal of Preventive Medicine, 45(5), 649-657. doi:10.1016/j.amepre.2013.08.001

McFadden, T., Fortier, M., \& Guérin, E. (2017). Investigating the effects of Physical Activity Counselling on depressive symptoms and physical activity in female undergraduate students with depression: A multiple baseline single-subject design. Mental Health and Physical Activity, 12, 25-36. doi:10.1016/j.mhpa.2017.01.002

Michie, S., Abraham, C., Whittington, C., McAteer, J., \& Gupta, S. (2009). Effective techniques in healthy eating and physical activity interventions: A meta-regression. Health Psychology, 28(6), 690-701. doi:10.1037/a0016136

Michie, S., Fixsen, D., Grimshaw, J. M., \& Eccles, M. P. (2009). Specifying and reporting complex behaviour change interventions: the need for a scientific method. Implementation Science, 4(1), 40. doi:10.1186/1748-5908-4-40

Michie, S., Ashford, S., Sniehotta, F. F., Dombrowski, S. U., Bishop, A., \& French, D. P. (2011). A refined taxonomy of behaviour change techniques to help people change their physical activity and healthy eating behaviours: the CALO-RE taxonomy. Psychology \& Health, 26(11), 1479-1498. doi:10.1080/08870446.2010.540664

Michie, S., Richardson, M., Johnston, M., Abraham, C., Francis, J., Hardeman, W., ... \& Wood, C. E. (2013). The behavior change technique taxonomy (v1) of 93 hierarchically clustered techniques: building an international consensus for the reporting of behavior change interventions. Annals of Behavioral Medicine, 46(1), 81-95. doi:10.1007/s12160013-9486-6 
Miller, W. R., \& Rollnick, S. (2013). Motivational Interviewing: Helping people change. New York. NY: Guilford.

Moore, C., Lee, J., Milligan, J., \& Giangregorio, L. (2015). Physical activity as medicine among family health teams: an environmental scan of physical activity services in an interdisciplinary primary care setting. Applied Physiology, Nutrition, and Metabolism, 40(3), 302-305. doi:10.1139/apnm-2014-0387

Naci, H., \& Ioannidis, J. P. (2013). Comparative effectiveness of exercise and drug interventions on mortality outcomes: metaepidemiological study. British Medical Journal. doi:10.1136/bmj.f5577

National Institute for Health and Care Excellence. (2013). Physical activity: brief advice for adults in primary care. Retrieved at: https://www.nice.org.uk/guidance/PH44/chapter/1Recommendations.

Ogden, J. (2016). Celebrating variability and a call to limit systematisation: The example of the behaviour change technique taxonomy and the behaviour change wheel. Health Psychology Review, 10(3), 245-250. doi: 10.1080/17437199.2016.1190291

O’Halloran, P. D., Blackstock, F., Shields, N., Holland, A., Iles, R., Kingsley, M., ... Taylor, N. F. (2014). Motivational interviewing to increase physical activity in people with chronic health conditions: A systematic review and meta-analysis. Clinical Rehabilitation, 28(12), 1159-1171. doi:10.1177/0269215514536210 
Olander, E. K., Fletcher, H., Williams, S., Atkinson, L., Turner, A., \& French, D. P. (2013). What are the most effective techniques in changing obese individuals' physical activity self-efficacy and behaviour: a systematic review and meta-analysis. International Journal of Behavioral Nutrition and Physical Activity, 10(1), 29.

Owen, K. B., Smith, J., Lubans, D. R., Ng, J. Y., \& Lonsdale, C. (2014). Self-determined motivation and physical activity in children and adolescents: A systematic review and meta-analysis. Preventive Medicine, 67, 270-279. doi:10.1016/j.ypmed.2014.07.033

Parker, A. G., Hetrick, S. E., Jorm, A. F., Mackinnon, A. J., McGorry, P. D., Yung, A. R., ...Purcell, R. (2016). The effectiveness of simple psychological and physical activity interventions for high prevalence mental health problems in young people: A factorial randomised controlled trial. Journal of Affective Disorders, 196, 200-209. doi:10.1016/j.jad.2016.02.043

Rhodes, R. E., \& Pfaeffli, L. A. (2010). Mediators of physical activity behaviour change among adult non-clinical populations: a review update. International Journal of Behavioral Nutrition and Physical Activity, 7(1), 37. doi:10.1186/1479-5868-7-37

Rubak, S., Sandbaek, A., Lauritzen, T., \& Christensen, B. (2005). Motivational interviewing: a systematic review and meta-analysis. The British Journal of General Practice: The Journal of the Royal College of General Practitioners, 55(513), 305-312. doi:10.1037//02786133.21 .5 .444

Ryan, R. M., \& Deci, E. L. (2000). Self-determination theory and the facilitation of intrinsic motivation, social development, and well-being. American Psychologist, 55(1), 68-78. doi:0.1037//0003-066X.55.1.68 
Samdal, G. B., Eide, G. E., Barth, T., Williams, G., \& Meland, E. (2017). Effective behaviour change techniques for physical activity and healthy eating in overweight and obese adults; systematic review and meta-regression analyses. International Journal of Behavioral Nutrition and Physical Activity, 14(1), 42. doi:10.1186/s12966-017-0494-y

Schuch, F., Vancampfort, D., Richards, J., Rosenbaum, S., Ward, P. B., \& Stubbs, B. (2016). Exercise as a treatment for depression: A meta-analysis adjusting for publication bias. Journal of Psychiatric Research, 77, 42-51. doi:10.1016/j.psychires.2016.02.023

Smith, D. M., Taylor, W., \& Lavender, T. (2016). Behaviour change techniques to change the postnatal eating and physical activity behaviours of women who are obese: a qualitative study. BJOG: An International Journal of Obstetrics \& Gynaecology, 123(2), 279-284. doi:10.1111/1471-0528.13751

Sniehotta, F. F. (2009). Towards a theory of intentional behaviour change: Plans, planning, and self-regulation. British Journal of Health Psychology, 14(2), 261-273. doi: $10.1348 / 135910708 X 389042$

Sniehotta, F. F., Schwarzer, R., Scholz, U., \& Schüz, B. (2005). Action planning and coping planning for long- term lifestyle change: theory and assessment. European Journal of Social Psychology, 35(4), 565-576. doi: 10.1002/ejsp.258

Teixeira, P. J., Carraça, E. V., Markland, D., Silva, M. N., \& Ryan, R. M. (2012). Exercise, physical activity, and self-determination theory: A systematic review. International Journal of Behavioral Nutrition and Physical Activity, 9(1), 78. doi:10.1186/1479-5868$9-78$ 
Vanbuskirk, K. A., \& Wetherell, J. L. (2014). Motivational interviewing with primary care populations: A systematic review and meta-analysis. Journal of Behavioral Medicine, 37(4), 768-780. doi:10.1007/s10865-013-9527-4

Webb, T. L., Joseph, J., Yardley, L., \& Michie, S. (2010). Using the internet to promote health behavior change: a systematic review and meta-analysis of the impact of theoretical basis, use of behavior change techniques, and mode of delivery on efficacy. Journal of Medical Internet Research, 12(1). doi:10.2196/jmir.1376

WHO. (2009). Global health risks: Mortality and Burden of Disease Attributable to Selected Major Risks.

WHO. (2017). Depression. Retrieved at: http://www.who.int/mediacentre/factsheets/fs369/en/ 


\section{Appendix S1}

\section{T棓DieR}

Template for Intervention Description and Replication
The TIDieR (Template for Intervention Description and Replication) Checklist Information to include when describing an intervention and the location of the information

Item Item
number

BRIEF NAME

1. Provide the name or a phrase that describes the intervention.

2. Describe any rationale, theory, or goal of the elements essential to the intervention.

3. Materials: Describe any physical or informational materials used in the intervention, including those provided to participants or used in intervention delivery or in training of intervention providers. Provide information on where the materials can be accessed (e.g., online appendix, URL).

4. Procedures: Describe each of the procedures, activities, and/or processes used in the intervention, including any enabling or support activities.
Physical Activity Counselling (PAC)

Physical Activity Counselling (PAC) aims to foster long-term physical activity participation through a Motivational Interviewing (MI) counselling style and the application of evidence-based behaviour change techniques (BCTs).

No material was provided to the recipients. The PAC intervention took the form of a conversation about physical activity behaviour change. The overarching purpose of this study was to describe the content (i.e., BCTs and $\mathrm{MI}$ techniques) as well as the relational style (i.e., MI relational techniques) within PAC sessions. These techniques are reported in the results section of the article.

The PAC intervention consisted of 2 individual PAC sessions delivered by student-counsellors to an insufficiently active client. Generally, the first PAC session was directed to resolve ambivalence and reinforce the clients' motivation to increase their physical activity levels. The second PAC session, which was delivered 2-4 weeks later, aimed at creating a physical activity plan if the client expressed being ready to do so (through change talk and intention). The PAC sessions included the delivery of behaviour change techniques and $\mathrm{MI}$ techniques.

The intervention recipients were approached by the studentcounsellors, as the delivery of the PAC sessions was required as part of a fourth year undergraduate course. 
Consent was obtained from clients for the recording of PAC sessions.

\section{WHO PROVIDED}

5. For each category of intervention provider (e.g., psychologist, nursing assistant), describe their expertise, background and any specific training given.

\section{HOW}

6. Describe the modes of delivery (e.g., face-to-face or by some other mechanism, such as internet or telephone) of the intervention and whether it was provided individually or in a group.

\section{WHERE}

7. Describe the type(s) of location(s) where the intervention occurred, including any necessary infrastructure or relevant features.
Criteria of included student-counsellors:

1. Upper-year undergraduate student on the path of becoming a Registered Kinesiologist.

2. Have completed the Physical Activity Counselling course at the University of $X$. The course focused on $\mathrm{MI}$ and physical activity behaviour change. The course was provided by an expert in physical activity motivation and behaviour change and included bi-weekly laboratory sessions.

3. Have delivered 2 PAC sessions to an insufficiently active and ambivalent client outside of their immediate social circle (e.g., friend of a friend).

4. Received a minimum grade of an $A(9.0)$ and ranked in the top 11 in the 2016 Physical Activity Counselling course.

The PAC sessions were one-on-one and were delivered face-to-face.

The PAC sessions were delivered at a place of convenience for the clients. The sessions occurred in a private location to facilitate an open discussion about change (e.g., house of client/counsellor, reserved room at the university, etc.)

Student-counsellors delivered 2 PAC sessions that lasted on average 49 minutes each. The PAC sessions took place at a time of convenience for the clients and there was an interval of 2-4 weeks between the PAC 1 and 2 sessions. 
9. If the intervention was planned to be personalised, titrated or adapted, then describe what, why, when, and how.

\section{MODIFICATIONS}

10. ${ }^{*}$ If the intervention was modified during the course of the study, describe the changes (what, why, when, and how).

\section{HOW WELL}

11. Planned: If intervention adherence or fidelity was assessed, describe how and by whom, and if any strategies were used to maintain or improve fidelity, describe them.

12. ${ }^{*} \quad$ Actual: If intervention adherence or fidelity was assessed, describe the extent to which the intervention was delivered as planned.
The PAC sessions were individually-adapted to the client's readiness to change, interests, motivations, goals, schedule, etc.

N/A

\section{N/A}

As no detailed PAC protocol exists and that this study was exploratory, fidelity was not assessed.

N/A

** Authors - use N/A if an item is not applicable for the intervention being described. Reviewers - use '?' if information about the element is not reported/not sufficiently reported.

+ If the information is not provided in the primary paper, give details of where this information is available. This may include locations such as a published protocol or other published papers (provide citation details) or a website (provide the URL).

\# If completing the TIDieR checklist for a protocol, these items are not relevant to the protocol and cannot be described until the study is complete.

* We strongly recommend using this checklist in conjunction with the TIDieR guide (see BMJ 2014;348:g1687) which contains an explanation and elaboration for each item.

* The focus of TIDieR is on reporting details of the intervention elements (and where relevant, comparison elements) of a study. Other elements and methodological features of studies are covered by other reporting statements and checklists and have not been duplicated as part of the TIDieR checklist. When a randomised trial is being reported, the TIDieR checklist should be used in conjunction with the CONSORT statement (see www.consort-statement.org) as an extension of Item $\mathbf{5}$ of the CONSORT 2010 Statement. When a clinical trial protocol is being reported, the TIDieR checklist should be used in conjunction with the SPIRIT statement as an extension of Item 11 of the SPIRIT 2013 Statement (see www.spirit-statement.org). For alternate study designs, TIDieR can be used in conjunction with the appropriate checklist for that study design (see www.equatornetwork.org). 


\section{List of Tables}

Table 1. Behaviour change techniques used by 11 student-counsellors in PAC sessions

\begin{tabular}{|c|c|c|c|c|c|c|c|c|c|c|c|c|c|c|c|}
\hline BCT no. & $\mathrm{BCT}$ & (1) & (2) & (3) & (4) & (5) & (6) & (7) & (8) & (9) & (10) & (11) & Total & PAC 1 & PAC 2 \\
\hline 3.1 & Social support (unspecified) & $\checkmark$ & $\checkmark$ & $\checkmark$ & $\checkmark$ & $\checkmark$ & $\checkmark$ & $\checkmark$ & $\checkmark$ & $\checkmark$ & $\checkmark$ & $\checkmark$ & 22 & 11 & 11 \\
\hline 1.1 & Goal setting (behaviour) & $\checkmark$ & & & $\checkmark$ & $\checkmark$ & $\checkmark$ & $\checkmark$ & $\checkmark$ & $\checkmark$ & $\checkmark$ & $\checkmark$ & 14 & 6 & 8 \\
\hline 8.1 & Behavioural practice/rehearsal & & $\checkmark$ & $\checkmark$ & $\checkmark$ & $\checkmark$ & $\checkmark$ & $\checkmark$ & $\checkmark$ & $\checkmark$ & $\checkmark$ & $\checkmark$ & 10 & 0 & 10 \\
\hline 1.2 & Problem solving & $\checkmark$ & $\checkmark$ & & $\checkmark$ & $\checkmark$ & $\checkmark$ & & $\checkmark$ & $\checkmark$ & & $\checkmark$ & 8 & 1 & 7 \\
\hline 1.4 & Action planning & $\checkmark$ & & & & & $\checkmark$ & $\checkmark$ & $\checkmark$ & $\checkmark$ & $\checkmark$ & $\checkmark$ & 8 & 2 & 6 \\
\hline 9.1 & Credible source & & $\checkmark$ & & $\checkmark$ & $\checkmark$ & $\checkmark$ & $\checkmark$ & $\checkmark$ & & $\checkmark$ & $\checkmark$ & 8 & 6 & 2 \\
\hline 13.4 & Valued self-identity & & $\checkmark$ & $\checkmark$ & & $\checkmark$ & & & $\checkmark$ & $\sqrt{ }$ & $\checkmark$ & $\checkmark$ & 7 & 7 & 0 \\
\hline 5.1 & Information about health consequences & & $\checkmark$ & & $\checkmark$ & $\checkmark$ & $\checkmark$ & & $\checkmark$ & & & $\checkmark$ & 6 & 5 & 1 \\
\hline 7.1 & Prompts/cues & & $\checkmark$ & & & & $\checkmark$ & $\checkmark$ & $\checkmark$ & $\checkmark$ & & $\checkmark$ & 6 & 0 & 6 \\
\hline 15.3 & Focus on past success & $\checkmark$ & $\checkmark$ & & & & & $\checkmark$ & $\checkmark$ & & $\checkmark$ & & 5 & 5 & 0 \\
\hline 6.2 & Social comparison & $\checkmark$ & & & & $\checkmark$ & & & $\checkmark$ & & & & 3 & 2 & 1 \\
\hline 10.6 & Non-specific incentive & & & & & & & $\checkmark$ & $\checkmark$ & $\checkmark$ & & & 3 & 0 & 3 \\
\hline 15.1 & Verbal persuasion about capability & & & & $\checkmark$ & & & $\checkmark$ & & $\checkmark$ & & & 3 & 1 & 3 \\
\hline 1.3 & Goal setting (outcome) & & & & & & & $\checkmark$ & & & & & 2 & 1 & 1 \\
\hline 1.5 & Review behaviour goals & & & & & & $\checkmark$ & & $\checkmark$ & & & & 2 & 0 & 2 \\
\hline 1.9 & Commitment & & & & & & $\checkmark$ & & $\checkmark$ & & & & 2 & 1 & 1 \\
\hline 2.3 & Self-monitoring of behaviour & & & & $\checkmark$ & & & & & & $\checkmark$ & & 2 & 1 & 1 \\
\hline 4.1 & Instruction on how to perform behaviour & & & $\checkmark$ & $\checkmark$ & & & & & & & & 2 & 0 & 2 \\
\hline
\end{tabular}




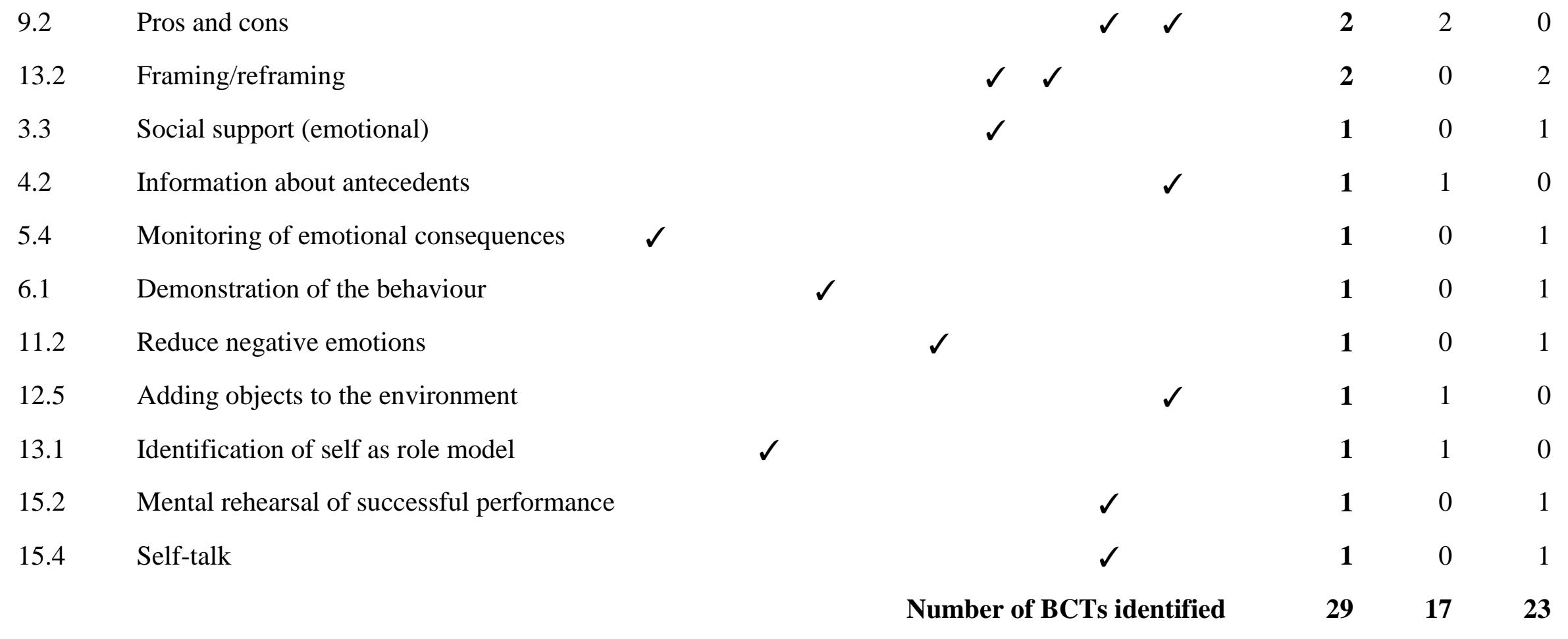


Table 2. Motivational Interviewing techniques used by 11 student-counsellors in PAC sessions

\begin{tabular}{|c|c|c|c|c|c|c|c|c|c|c|c|c|c|c|c|}
\hline no. & MI technique & (1) & (2) & (3) & (4) & (5) & (6) & (7) & (8) & (9) & (10) & (11) & Total & PAC 1 & PAC 2 \\
\hline 3 & Reflective statements & $\checkmark$ & $\checkmark$ & $\checkmark$ & $\checkmark$ & $\checkmark$ & $\checkmark$ & $\checkmark$ & $\checkmark$ & $\checkmark$ & $\checkmark$ & $\checkmark$ & 22 & 11 & 11 \\
\hline 24 & Emphasise autonomy & $\checkmark$ & $\checkmark$ & $\checkmark$ & $\checkmark$ & $\checkmark$ & $\checkmark$ & $\checkmark$ & $\checkmark$ & $\checkmark$ & $\checkmark$ & $\checkmark$ & 21 & 11 & 10 \\
\hline 1 & Open-ended questions & $\checkmark$ & $\checkmark$ & $\checkmark$ & $\checkmark$ & $\checkmark$ & $\checkmark$ & $\checkmark$ & $\checkmark$ & $\checkmark$ & $\checkmark$ & $\checkmark$ & 20 & 10 & 10 \\
\hline 2 & Affirmation & $\checkmark$ & $\checkmark$ & $\checkmark$ & $\checkmark$ & $\checkmark$ & $\checkmark$ & $\checkmark$ & $\checkmark$ & $\checkmark$ & $\checkmark$ & $\checkmark$ & 19 & 9 & 10 \\
\hline 7 & Permission to provide information and advice & $\checkmark$ & $\checkmark$ & $\checkmark$ & $\checkmark$ & $\checkmark$ & $\checkmark$ & $\checkmark$ & & $\checkmark$ & $\checkmark$ & $\checkmark$ & 13 & 8 & 5 \\
\hline 35 & Support change/persistence & $\checkmark$ & $\checkmark$ & $\checkmark$ & $\checkmark$ & $\checkmark$ & $\checkmark$ & $\checkmark$ & $\checkmark$ & $\checkmark$ & $\checkmark$ & $\checkmark$ & 13 & 11 & 2 \\
\hline 6 & Review a typical day & & $\checkmark$ & $\checkmark$ & $\checkmark$ & $\checkmark$ & $\checkmark$ & $\checkmark$ & $\checkmark$ & $\checkmark$ & $\checkmark$ & & 10 & 8 & 2 \\
\hline 11 & Confidence ruler & $\checkmark$ & & & & $\checkmark$ & $\checkmark$ & $\checkmark$ & $\checkmark$ & $\checkmark$ & & $\checkmark$ & 10 & 6 & 4 \\
\hline 15 & Hypothetical thinking & $\checkmark$ & & & & $\checkmark$ & $\checkmark$ & & $\checkmark$ & $\checkmark$ & & & 5 & 1 & 4 \\
\hline 17 & Identify past successes & $\checkmark$ & $\checkmark$ & & & & & $\checkmark$ & $\checkmark$ & & $\checkmark$ & & 5 & 5 & 0 \\
\hline 20 & Troubleshooting & $\checkmark$ & & & & $\checkmark$ & & & $\checkmark$ & $\checkmark$ & & $\checkmark$ & 5 & 0 & 5 \\
\hline 23 & Double-sided reflection & $\checkmark$ & & & $\checkmark$ & $\checkmark$ & & & & $\checkmark$ & & & 5 & 3 & 2 \\
\hline 8 & Elicit-Provide-Elicit & & & & $\checkmark$ & & $\checkmark$ & & & & & $\checkmark$ & 3 & 3 & 0 \\
\hline 10 & Importance ruler & $\checkmark$ & $\checkmark$ & & & & & & & $\checkmark$ & & & 3 & 2 & 1 \\
\hline 12 & DARN questions & & & & $\checkmark$ & $\checkmark$ & & & & & & & 3 & 2 & 1 \\
\hline
\end{tabular}




$\begin{array}{ll}19 & \text { Brainstorming } \\ 31 & \text { Explore change expectations } \\ 22 & \text { Reframing } \\ 36 & \text { Offer emotional support } \\ 5 & \text { Agenda mapping } \\ 18 & \text { Identify strengths } \\ 25 & \text { Overshooting } \\ 32 & \text { Consider change options }\end{array}$

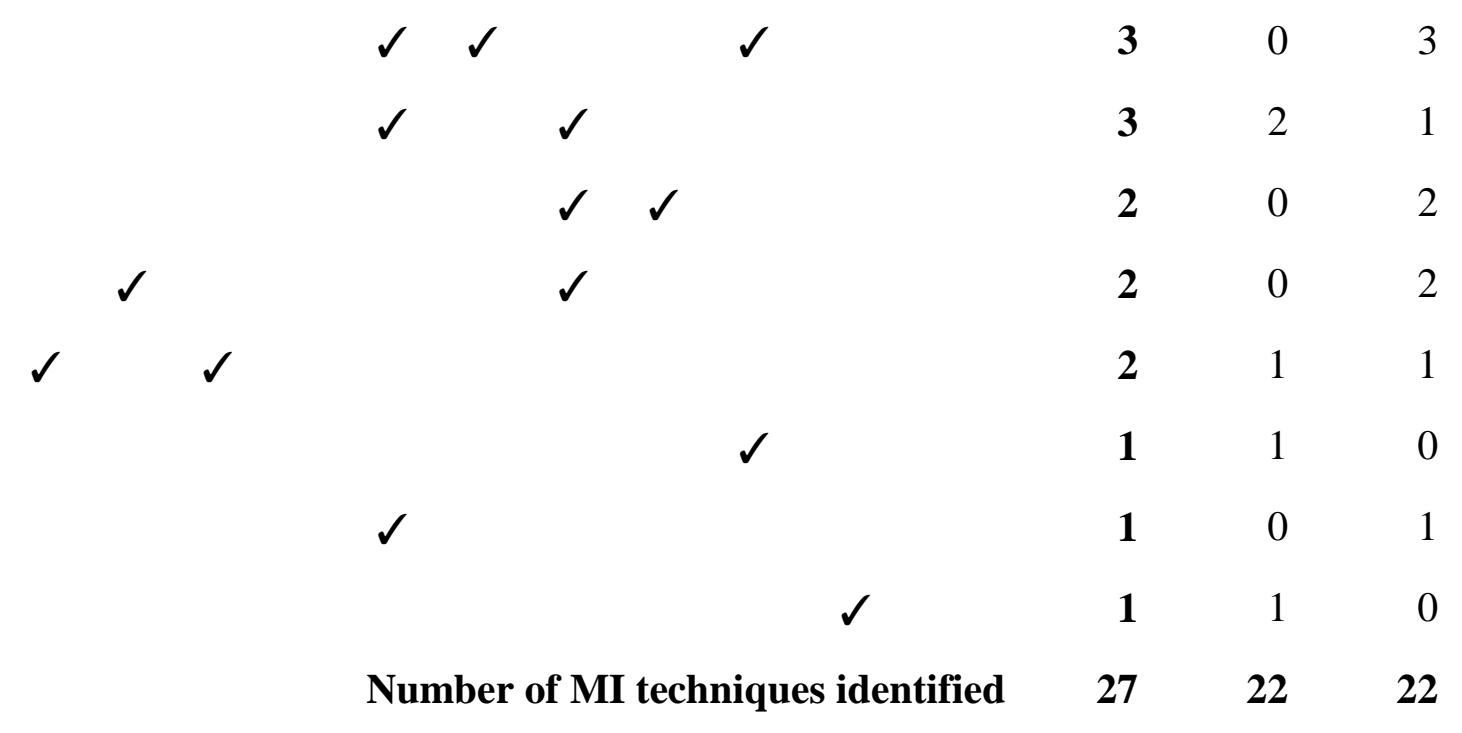


Table 3. Number of different BCTs and MI techniques identified in PAC 1 and PAC 2 sessions

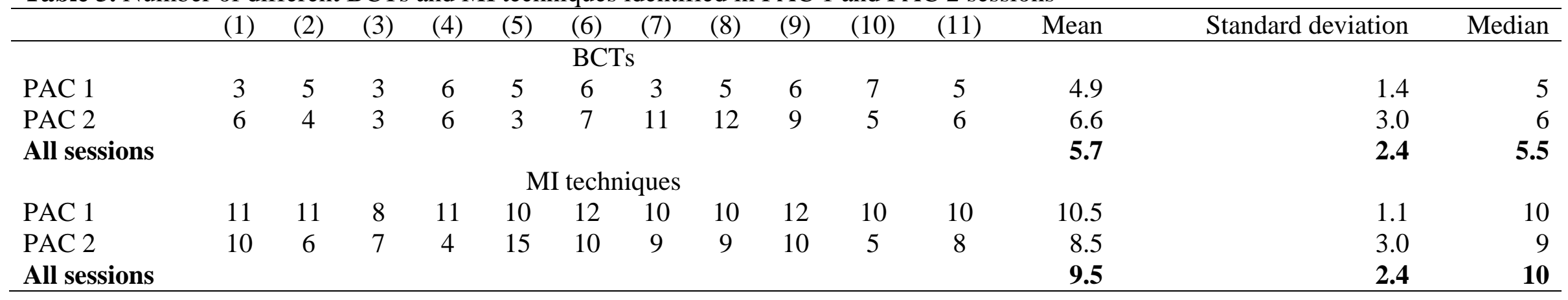




\section{List of Figures}

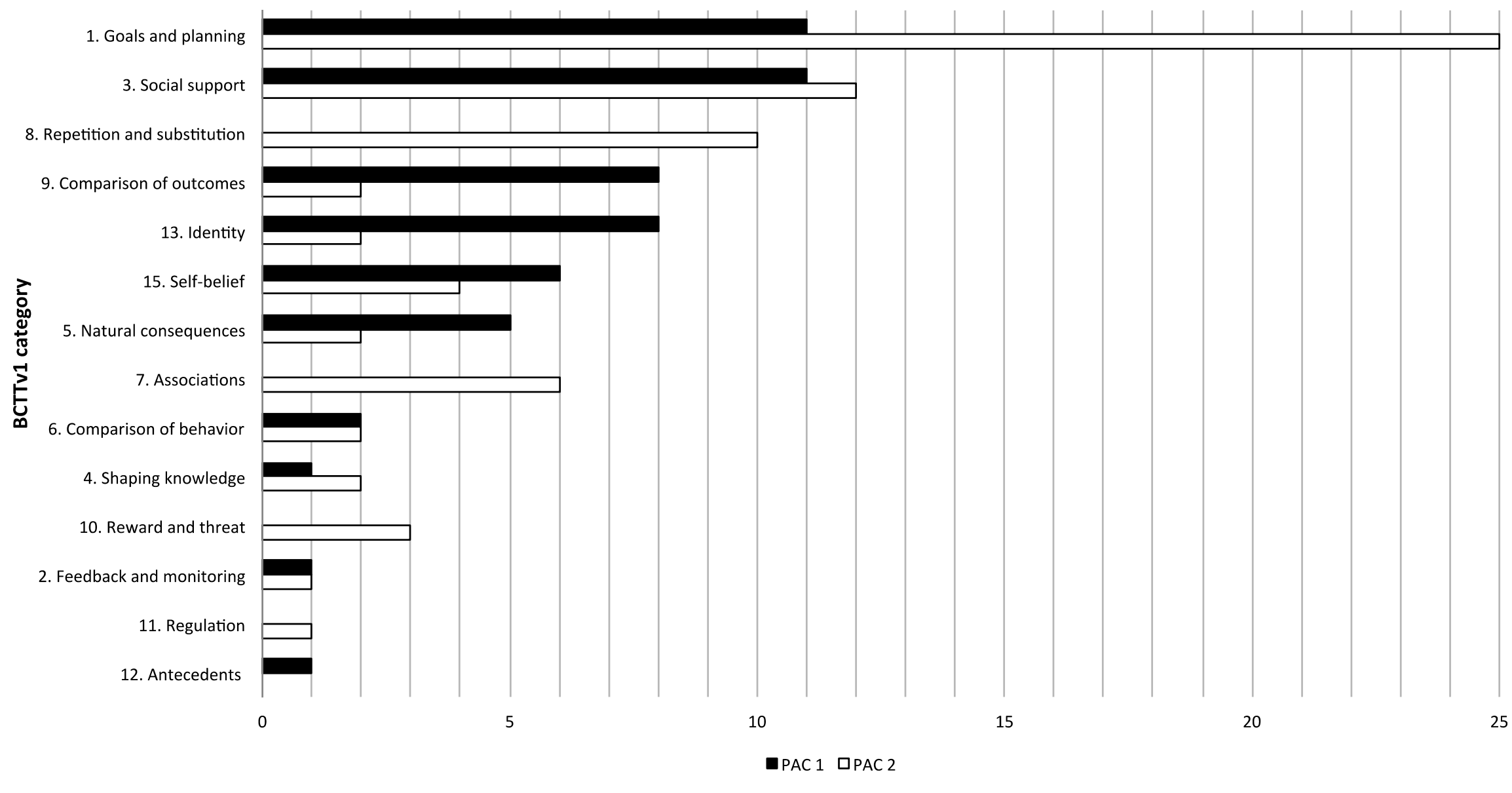

Frequency of use

Figure 1. Frequency of coding BCTs belonging to each BCTTv1 category across PAC 1 and PAC 2 sessions. Note. The results in the figure were obtained by totaling the number of BCTs used across PAC 1 and PAC 2 sessions for each BCT category. 


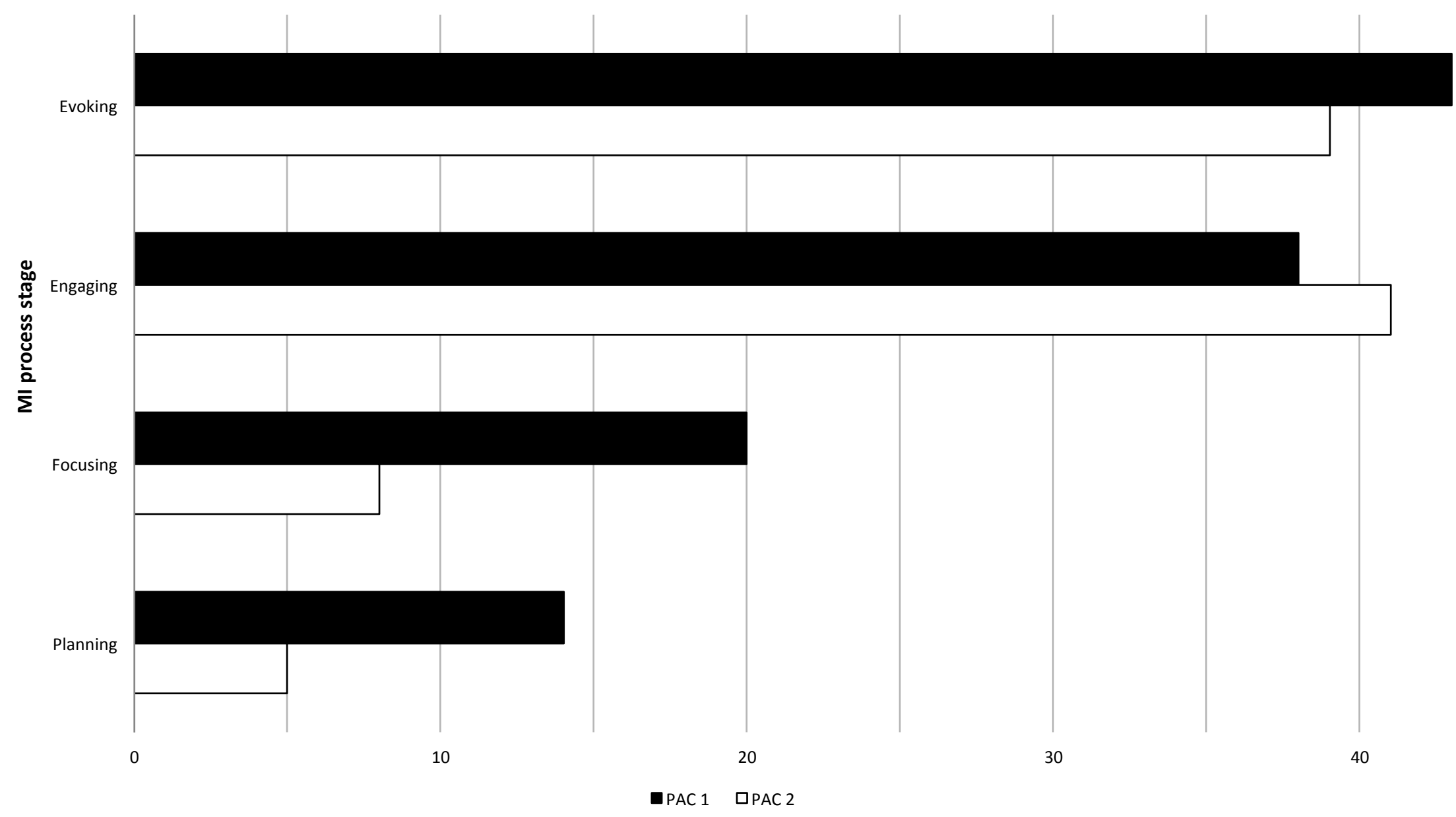

Frequency of use

Figure 2. Frequency of coding MI techniques belonging to each MI process stage across PAC 1 and PAC 2 sessions. Note. The results in the figure were obtained by totaling the number of MI techniques used across PAC 1 and PAC 2 sessions for each MI process stage. 


\section{CHAPTER IV: GENERAL DISCUSSION}

The overarching purpose of this dissertation was to provide an in-depth description of a Physical Activity Counselling (PAC) intervention through the identification of behaviour change techniques (BCTs) and Motivational Interviewing (MI) techniques applied across a sample of 22 PAC sessions. Overall, analyses revealed that PAC delivered by student-counsellors incorporates a wide range of BCTs and MI techniques (refer to Chapter III). First, the present chapter will present conflicting perspectives about the field of health behaviour change. Then, an interpretation of the study's findings will be provided with respect to previous research and theory. Subsequently, strengths, practical applications, limitations, and future research directions will be discussed.

\section{Health Behaviour Change: Recognizing the Need for Flexibility}

Health behaviour change is a scientific field that has gained much attention in recent years. Systematic methods for specifying the content of interventions (i.e., BCTTv1) and guiding intervention design (i.e., Behaviour Change Wheel; Michie, van Stralen, \& West, 2011) have emerged and have been particularly useful in advancing the current state of knowledge. As the present study was concerned with reporting the content and relational style of a PAC intervention, the BCTTv1 and the table of MI techniques have proved helpful in achieving this purpose. Indeed, such taxonomies carry several functions, namely 1) exploring which techniques are used in interventions and 2) identifying which techniques are most effective in changing some target behaviour (Michie et al., 2013). Ultimately, such systematic tools can allow cumulating evidence across intervention studies and, in turn, promote evidence-based practice.

As PAC is framed as an individually-adapted behaviour change intervention aiming to motivate individuals to become more physically active for their own reasons, one might question 
why valid and standard taxonomies are warranted. This perspective was brought forth in a recent commentary by Ogden (2016), in which she made a call to limit systematization and celebrate variability. She argues that:

the goal to specify which intervention tools should be used for a specific behaviour ignores the need for flexibility, variability and change according to not the type of behaviour, or the type of intervention or even the type of patient but how that individual patient happens to feel, think, look, behave or respond at any particular time (p. 248). Ogden`s point is a valuable one, as variability will always exist to some extent in respect to both the client and the health professional. If we systematize everything, professionals will turn into technicians, which is undesirable.

On the other hand, as stressed by Teixeira (2016), health behaviour change is a new scientific field and the creation of knowledge that will arise from the adoption of such systematic approaches will contribute the improve interventions and stimulate progress in the field. For instance, evidence-based PAC protocols can be developed and guide the implementation of effective PAC in practice. We must note, however, that the complex and "messy" nature of behaviour change interventions and the inherent characteristics of clients will force health professionals to remain flexible and rely on prior experience and other sources of information to make sound decisions in a particular context. With this in mind, PAC protocols that will emanate from future research will be highly valuable and informative but must remain adaptable and flexible.

\section{What Did We Find and What Does it Mean?}

Behaviour change techniques. In total, $29 \mathrm{BCTs}$ were reliably identified across all PAC sessions, accounting for approximately a third of the whole array of BCTs in the BCTTv1. To 
begin, 3.1 Social support (unspecified) was recorded in each PAC session, which is logical as this is the BCT that refers to MI. This BCT was also expressed during PAC sessions when, for example, the student-counsellor prompted his or her client to arrange social support (e.g., from friends, family, colleagues) for the purpose of facilitating engagement in PA. Although unsurprising, this finding is promising as previous research suggested that providing or planning for social support was associated with increased PA behaviour change and weight loss (Greaves et al., 2011; Hankonen et al., 2015). From a Cognitive Evaluation Theory standpoint, the student-counsellors' provision of social support might have facilitated PA behaviour change through fostering their client's need for relatedness. This idea is further developed later in this chapter.

Additionally, self-regulation BCTs were recorded frequently across the sampled PAC sessions. Self-regulation is a broad term describing any of the psychological processes (i.e., thoughts, feelings, and behaviours) involved in the pursuit of goals (Mann, Fujita, \& de Ridder, 2013). Experts agree that self-regulation can be broken down into two main components: goal setting and goal striving (Carver \& Scheier, 1982; Mischel, Cantor, \& Feldman, 1996). Goal setting refers to specifying a goal one desires to attain and the criteria for judging success (Mann et al., 2013). This initial step in self-regulation was satisfied in PAC sessions as the second most frequently documented BCT was 1.1 Goal setting (behaviour). This finding is encouraging since previous research supported the effectiveness of goal setting for positive PA outcomes (Greaves et al., 2011; Hankonen et al., 2015). We must note, however, that one's ability to engage in selfregulation and attain goals can be influenced by certain characteristics inherent to those goals. For instance, research suggests that individuals attempting to achieve approach over avoidance goals, mastery over performance goals, and challenging yet realistic versus easy goals are more 
likely to be effective in goal pursuit (Mann et al., 2013). Coding tools such as the BCTTv1 do not appreciate all the particularities inherent to BCTs (e.g., type of goals) and interventionists would do well to promote the formulation of quality goals (e.g. SMART goals) to enhance the likelihood of positive intervention outcomes.

The second component of self-regulation, goal striving, involves the strategies or actions promoting goal attainment and protecting the goal from distraction or disruption (Mann et al., 2013). The BCTs 1.4 Action planning and 1.2 Problem solving are well known self-regulation BCTs in goal striving, each receiving 8 codes across our sample with most coming from PAC 2 sessions. These techniques have been researched extensively and have been shown to be important strategies to bridge the PA intention-behaviour gap (Carraro \& Gaudreau, 2013; Rhodes \& DeBruijn, 2013; Sniehotta, Scholz, Schwarzer, 2005). Moreover, a recent metaanalytic review of physical activity interventions revealed that action plans are most effective when a barrier management component is integrated to them (Bélanger-Gravel, Godin, \& Amireault, 2013). The marked presence of action planning and problem solving observed in this study is therefore encouraging, and indicates that the student-counsellors often combined these two during the PAC 2 session and thus assisted the clients with these important self-regulation techniques.

On the less encouraging side, it was surprising that 2.3 Self-monitoring of behaviour was not frequently coded. Indeed, self-monitoring is an essential self-regulatory skill allowing to adjust a behavioural response according to the perceived discrepancy between current and desired states (Carver \& Scheier, 1982; Zimmerman, 2006). While goals and planning BCTs were frequent among the sampled sessions, the BCT 2.3 Self-monitoring of behaviour was rarely prompted by the student-counsellors, with only 2 codes out of 22 PAC sessions analyzed. 
As stated earlier in this dissertation, Zimmerman and Campillo (2003) proposed a cyclical model to illustrate the phases and subprocesses of self-regulation. Our findings demonstrate that the PAC sessions partially supported self-regulation, as BCTs aligning with the forethought phase (i.e., 1.1 Goal setting (behaviour), 1.2 Problem solving, and 1.4 Action planning) were emphasized while little attention was given to subsequent self-regulatory phases. The application of more BCTs aligning with the performance and self-reflection phases (e.g., 2.3 Self-monitoring of behaviour, 15.4 Self talk, 4.3 Re-attribution, 13.2 Framing/reframing, and 13.5 Identity associated with changed behaviour) might be helpful in fostering self-regulation skills in clients receiving PAC sessions. Interestingly, previous studies reported that people were more likely to adopt health goals and be better self-regulators if they had an intrinsic interest (i.e., self-determined motivation) in changing the behaviour (Koestner, Lekes, Powers, \& Chicoine, 2002; Pelletier, Dion, Slovinec-D’Angelo, \& Reid, 2004). Therefore, PAC trainers might do well to emphasize the aforementioned techniques given the body of evidence supporting self-regulation for PA behaviour change.

In a different line of thought, the wide presence of the BCT 8.1 Behavioural practice/rehearsal in PAC 2 sessions was perhaps one of the most encouraging findings of this study. According to our results, the majority of clients (10 out of 11) reported having increased their PA after the PAC 1 session, potentially resulting from the discussions that took place during the intervention. Undeniably, such causal link cannot be established given the exploratory nature of this study. Also, the identification of this BCT was completely reliant on the clients' verbal statements and could not be ascertained, as the practice of PA occurred outside of the PAC intervention. This notwithstanding, it is conceivable that PA initiation was made possible in part by the provided support and guidance from our student-counsellors. 
Motivational Interviewing techniques. The examination of MI content and relational techniques in PAC sessions was made possible by using the first conceptual list of MI techniques (Hardcastle et al., 2017). As stressed by Hagger and Hardcastle (2014), increased attention should be given to the relational style through which content-based techniques are delivered in interventions. Luckily, the work of Hardcastle and colleagues (2017) allows for the investigation of relational techniques in MI interventions. As per Hagger and Hardcastle's recommendations (2014), our study was the first to specify relational techniques in addition to reporting the content-based techniques of an intervention.

Overall, $27 \mathrm{MI}$ techniques were reported in the sample sessions, which represent more than $70 \%$ of the possible $38 \mathrm{MI}$ techniques. Our analyses showed that the core relational skills of MI (i.e., open-ended questions, affirmations, reflective and summary statements) were applied in almost all of the coded PAC sessions. Hence, this provides initial support that studentcounsellors adhered to the MI approach in their delivery of PAC sessions. We must note, however, that the present study only assessed the presence and did not measure how often OARS skills were applied within each session. Since these fundamental relational techniques should be utilized often across the four stages of the MI process (Miller \& Rollnick, 2013), and determining the presence/absence of these techniques is not sufficient to document the fidelity in PAC delivery, we recommend future intervention studies to report the frequency of identified MI techniques.

On another note, giving information and advice was common during the PAC sessions. The MI relational technique 7. Permission to provide information and advice can optimize the delivery of information and advice from a counsellor so that it is being well received by the client. Indeed, simply asking permission prior to giving information has several positive 
functions such as lowering resistance, honouring the client's autonomy, and promoting a good collaborative relationship with the client (Miller \& Rollnick, 2013). In turn, this might have promoted the clients' active involvement in the PAC sessions. Despite less frequent, common MI content techniques included 11. Confidence ruler, 21. Values exploration, and 30. Normalizing. Unsurprisingly, all of these are designed to facilitate the evocation of client change talk, the proposed mediator of change in MI (Miller \& Rose, 2009).

As mentioned earlier in this dissertation, Self-Determination Theory (SDT) and MI have been proposed as compatible frameworks, leading experts to think that a formal marriage between the two models would ensue (Teixeira, Palmeira, \& Vansteenkiste, 2012). In efforts to assign SDT as the theoretical framework of MI, and MI as the intervention approach of SDT, previous research has proposed a Cognitive Evaluation Theory lens to explain the paths through which MI components may promote health behaviour change (Fortier et al., 2007; Markland, Ryan, Tobin, \& Rollnick, 2005; Resnicow \& McMaster, 2012). This involved linking MI intervention components from Miller and Rollnick's conceptualization of MI (2002) to the psychological needs of autonomy, competence, and relatedness. In order to extend this work, we have linked MI techniques documented in this study to the corresponding psychological need(s) we posit they act upon (refer to Appendix F).

For instance, student-counsellors promoted the need of autonomy through 7. Permission to provide information and by prompting the client to come up with ideas to increase their PA (i.e., 15. Hypothetical thinking, 19. Brainstorming). Furthermore, the student-counsellors promoted feelings of competence with genuine statements acknowledging the client's strengths and efforts in the direction of behaviour change (i.e., 2. Affirmation) and by normalizing difficulties encountered by clients in their quest to become more physically active. Finally, the 
need for relatedness was promoted through questioning the clients about their most cherished values and life goals (i.e., 21. Values exploration) as well as offering emotional support and reassurance.

Additionally, Organismic Integration Theory represents a valuable framework for understanding the manner through which values exploration exerts its effect. Indeed, 21. Values exploration is a MI content technique that can facilitate the transformation of extrinsicallyregulated motives into more self-determined ones. In the context of PAC specifically, this technique entails prompting a client to explore his or her values and reflect on how PA is congruent (or not) with these. Through this technique, integrated regulation by which a behaviour aligns with one's values and aspirations is supported. The frequent application of this technique is encouraging as a recent meta-analysis revealed that integrated regulations positively predict PA behaviours (Teixeira, Carraça et al., 2012).

Quantity of BCTs and MI techniques applied in PAC sessions. Analyses revealed an average of 5.7 BCTs per PAC session (6.6 PAC 1 vs. 4.9 PAC 2), similarly to that reported in a meta-analysis of healthy eating and PA interventions (i.e., 6.0 BCTs; Michie, Ashford et al., 2009). Research has found that the quantity of BCTs may represent an important predictor of effective PA interventions (Cradock et al., 2017; Webb et al., 2010). Indeed, experts have postulated that including a greater variety of BCTs may lead to better outcomes since it allows approaching behaviour change from different angles (Ritterband et al., 2009). Also, relying on a greater pool of techniques represents an interesting strategy given that not every client will respond to them in the same way (Chatzisarantis \& Hagger, 2007). Hence, the likelihood of delivering the BCTs that successfully trigger behaviour change could increase. 
Conversely, PAC sessions included on average 9.5 MI techniques. Since the clients' perceptions of their relationship with a provider positively predict intervention outcomes (CritsChristoph et al., 2011), it is essential to create a strong and trusting rapport with the client before narrowing down the conversation and getting into the 'content' of the intervention (Miller \& Rollnick, 2013). This is supported by our results, as many MI relational techniques were documented in PAC 1 sessions. As the intervention unfolds, the MI counsellor progressively transitions into subsequent stages of the MI process in which the application MI content techniques (e.g., 15. Hypothetical thinking, 20. Troubleshooting) and BCTs (e.g., goal setting, action and coping planning) is appropriate (Miller \& Rollnick, 2013). This can provide an explanation as to why a there was a trend towards a greater number of MI techniques in PAC 1 sessions (i.e., 10.5 vs. 8.5 for PAC 2) and a higher prevalence of BCTs in PAC 2 sessions (i.e., 6.6 vs. 4.9 for PAC 1).

BCT categories and MI process stages. From a BCTTv1 standpoint, Goals and planning (1) and Social support (3) were the primary mechanisms of change targeted in PAC 1 and 2 sessions, due to the consistent application of 1.1 Goal setting (behaviour), 1.2 Problem solving, 1.4 Action planning, and 3.1 Social support (unspecified). On the contrary, none or very few BCTs were drawn from several other BCT categories, notably Antecedents (12), Scheduled consequences (14), and Covert learning (16). This finding might point to novel avenues for promoting PA initiation and maintenance in PAC.

From a MI standpoint, Evoking and Engaging stages of MI were prioritized in the PAC sessions. The high prevalence of Evoking techniques can be explained by the fact that eliciting client change talk is crucial in MI, hence the fact that 22 out of the 38 MI techniques are classified as Evoking techniques. This is logical as such techniques encourage client change talk, 
which is essential at the beginning of the change process and which is the predicted mediator of change in MI (Miller \& Rose, 2009). Engaging techniques are represented by the communication style of MI (i.e., OARS skills) and should be applied across the entire intervention. Despite being categorized strictly as Engaging techniques, OARS are fundamental techniques to maintaining a collaborative relationship with the client throughout the intervention (Appendix B). Therefore, it is encouraging that all Engaging techniques were present in the vast majority of PAC 1 and 2 sessions.

Surprisingly, analyses revealed that MI techniques falling under the Planning stage were more frequent in PAC 1 sessions. This is contradictory to our finding that goal and planningoriented BCTs were more frequent in PAC 2 sessions. However, the predominant MI planning technique was 35. Support change/persistence, which received 11 out of its 13 codes in PAC 1 sessions. As a matter of fact, this technique was recorded at the very beginning of PAC 1 sessions when counsellors described their roles (i.e., counsellor functions as a partner collaborating with the client's expertise, role of support in behaviour change process, etc.). In this case, the technique was actually utilized in the Engaging stage as opposed to the Planning stage of the PAC intervention. This particular example, in addition to OARS skills, suggests that the classification of techniques in Hardcastle and colleagues' taxonomy (2017) might be too rigid and that MI techniques can be applied across the different process stages. Future research might wish to examine this more closely.

\section{Strengths}

There are a number of methodological, knowledge, and practical implications arising from this dissertation. First, the internationally validated BCTTv1 was employed to document the content of PAC 1 and 2 sessions delivered by student-counsellors. This highly recognized 
method for reporting intervention content did not only allow painting a picture of individual BCTs present in PAC sessions, but also provided insight on the general mechanisms of change targeted (i.e., BCT categories) to promote PA.

Second, our investigation has gone beyond the mere identification of BCTs by reporting MI techniques included in PAC sessions. To our knowledge, the present study represents the first attempt to code an intervention using the recently published table of MI techniques (Hardcastle et al., 2017). This is particularly relevant, as the reporting of PAC sessions based on this coding instrument enabled the observation of relational techniques, which are too often overlooked in intervention studies (Hagger \& Hardcastle, 2014; Samdal et al., 2017).

Third, the identification of BCTs and MI techniques was based on the observation of videotaped PAC sessions. Indeed, the use of videotapes is the gold standard for objective verification of intervention delivery (Borelli, 2011). In contrast, studies rating the presence/absence of techniques based on a priori text descriptions (e.g., Olander et al., 2013) are increasingly affected by experimenter's bias. In this case, experimenter's bias would reflect a tendency to report techniques that align with the researcher's conception of how the evaluated intervention should be delivered. Additionally, the double coding of PAC sessions and the corresponding inter coder agreement scores provided strong support for the reliability of our findings. Taken together, these methodological strategies enhanced the trustworthiness of our conclusions.

Fourth, the sample size (i.e., 22 sessions) represents a notable strength of this dissertation, as it was greater to that used in previous studies of similar kind (Gainforth et al., 2016; Smith, Taylor, \& Lavender, 2015). As no additional BCT or MI technique was identified in the final 3 PAC sessions coded, it is reasonable to assume that data saturation was reached and that sample 
size was appropriate.

Finally, the endorsement of the TIDieR guidelines allowed for a comprehensive representation of the PAC sessions. Adherence to such guidelines ensures the completeness of reporting and ultimately aids in replication of effective interventions (Hoffman et al., 2014). The adoption of the latest coding tools and guidelines in this dissertation allowed providing a thorough account of the active ingredients included in PAC sessions, something that was unprecedented. Although the effectiveness of the PAC sessions and of individual techniques applied within them was not assessed, this dissertation provides an exemplar for future intervention studies of this kind.

In addition to these strengths, this dissertation is fruitful on the applied side as well.

\section{Practical Applications}

Indeed, useful insights for practice arise based on the study's results. To begin, our findings provide initial guidance as to the specific BCTs and MI techniques that can be utilized during client consultations to promote PA. Despite that the effectiveness of these individual techniques in PAC remains unexplored, our results can help health providers gain insight in terms of how they can go about carrying PAC with their patients. For instance, the application of OARS skills, recognizing the client's autonomy as well as prompting goal setting, action planning, and problem solving are seemingly well suited for the delivery of PAC.

To continue, the results obtained from this study lay the groundwork for the development of PAC protocols. In a review of health providers' perceptions of PAC, the lack of counselling protocols and the lack of knowledge/training on the topic are two of the most frequently reported barriers to counselling patients on PA (Hébert, Caughy, \& Shuval, 2012). With upcoming studies evaluating the impact of individual techniques on PAC outcomes, the elaboration of a protocol 
for effective PAC interventions would play a critical role in improving the implementation of PAC across clinical care.

A more proximal application stemming from this dissertation concerns the training in PAC. By comparing the active ingredients observed in the sampled sessions with the current body of evidence on effective techniques for PA behaviour change, we were able to highlight some BCTs and MI techniques currently being overlooked and which may benefit from increased attention. Based on our conclusions, we recommend that university professors teaching PAC-related courses place greater emphasis on the techniques 2.3 Self-monitoring of behaviour (e.g., use of PA logbooks, pedometers, etc.) and 9.2 Pros and cons (MI technique: 9. Running head start). As such, our findings propose concrete ways to improve PAC training, and subsequently improve PAC outcomes.

\section{Limitations and Future Research Directions}

As with every study, a number of limitations are worth noting. First, the coders rated the presence of BCTs and MI techniques only, providing no indication regarding how well the techniques were delivered (i.e., quality). While the operationalization criteria of each technique are well defined in taxonomies, the delivery of these techniques can vary substantially. For example, the BCT 1.4 Action planning can be as simple as defining the intensity at which the behavioural goal will be performed, or as complex as creating detailed if-then plans (Michie et al., 2013).

Second, the coding protocol applied did not permit differentiation between counsellordelivered and client-initiated techniques. In MI, it is paramount to let the clients select their own strategies for behaviour change (Miller \& Rollnick, 2013). As PAC is based on MI, some of the techniques were brought forward by the client, rather than from the student-counsellor. Given the 
complex nature of behaviour change interventions and the important role played by the client, methods in the field have been proposed to account for the clients' statements and the temporal patterns such as sequencing and duration of individual techniques (Gainforth et al., 2016; Hollenstein, 2007). In line with these recent developments, researchers might do well to study interventions as dynamic systems instead of viewing them solely from an interventionist perspective.

Third, assessing the effects of the PAC sessions and of individual techniques was outside the scope of this dissertation, thereby limiting recommendations to be made for practice. Therefore, we recommend future studies to employ randomized and longitudinal designs to determine the BCTs and MI techniques conducing to effective PA initiation and maintenance. In addition, these studies should address relational techniques and their relationships with contentbased techniques in order to evaluate the effectiveness of complex interventions such as PAC.

The fourth limitation relates to the characteristics of participating counsellors. On one hand, student-counsellors were newly trained in MI and PA behaviour change, making them novice counsellors. Their limited experience in providing PAC might have influenced the selection of BCTs and MI techniques during their sessions as well as the variety/quantity of techniques they applied. Hypothetically, student-counsellors less confident in evoking client change talk might leapfrog certain stages of the MI process and transition too quickly in goal setting and other planning techniques. Similarly, this may impede on the variety of techniques that can be applied. On the other hand, all student-counsellors in this study received unique training as they were enrolled in the same course. Since PAC training may differ across academic institutions, the generalizability of our results is limited. In light of these considerations, future research should investigate PAC sessions delivered by experienced 
Kinesiologists working in primary care settings and having been trained in different institutions. This would therefore fill a gap in knowledge and highlight the disparities existing between novice and experienced counsellors.

Fifth and last, our findings do not portray the full length of the PAC intervention. Indeed, PAC interventions generally include more than 2 sessions, as suggested by a recent study reporting an average of 6.2 PAC sessions per client (McFadden et al., 2017). Consequently, it is reasonable to assume that the reported BCTs and MI techniques were steered more towards motivation evocation and PA initiation. The examination of the full length of the intervention would allow for the exploration of additional techniques, notably those directed towards PA maintenance.

Additional directions for future research are worthy of consideration. One derives from the observation of the average length of PAC sessions (i.e., 49 minutes). In a health care system advocating for cost-effectiveness and efficiency (Muennig \& Bounthavong, 2016), it is paramount that interventions produce desired outcomes with the least amount of time and effort. Knowing that a PAC intervention is particularly lengthy (i.e., requires multiple sessions that can last up to an hour each), researchers should focus on developing and evaluating different strategies to 'sell' effective PAC interventions to policy decision makers. For instance, the " 7 A's model" for interdisciplinary shared care is one approach that can be used to integrate PAC in primary care, whereby a physician addresses the topic of PA with a patient before referring him or her to a PA counsellor, if need be (Fortier et al., 2007). The evaluation of such strategies could in turn promote effective implementation and scaling up of PAC in health care.

Current work is in progress to identify SDT techniques used in interventions and classify them according to the psychological need they address (Texeira \& Hagger, 2016). Preliminary 
findings revealed a total of 26 SDT techniques designed to promote self-determined motivation and sustained behaviour change. Future research investigating SDT-informed interventions such as PAC should therefore document the techniques presented in this work, which is expected to be published shortly. This would increase our potential for understanding PA behaviour change on the basis of SDT processes. However, the proliferation of coding instruments and guidelines might lead to challenges in terms of coder burden. In order to overcome these, researchers might do well to be more inclusive rather than working independently. One tangible way to do so and reduce coder burden would be to incorporate $\mathrm{MI}$ and SDT techniques to future iterations of the BCTT.

Finally, future research might wish to examine the nature of the relationship between the content and relational components of PAC and other behaviour change interventions. Are content-based techniques more important than relational techniques? Do relational techniques moderate the effectiveness of content-based techniques? Such interrogations might also extend in regards to the correlation between the quantity of techniques and the effectiveness of interventions. Are more techniques always better? Is there a threshold of effectiveness (i.e., an inverted $U$ effect)? Answers to such questions will certainly vary according to a variety of factors, but might stimulate good reflections and debate on the matter.

\section{Conclusion}

Previous research has demonstrated the positive impact of PAC on physical activity levels (Fortier et al., 2011; Gao et al., 2016) and depressive symptoms (McFadden et al., 2017). However, the active ingredients included in PAC remained unreported, which hampered our ability to identify the exact mechanisms resulting in their effectiveness. Therefore, this study 
sought to explore the BCTs and MI techniques applied in PAC 1 and 2 sessions delivered by student-counsellors in order to paint a detailed picture of the content and relational style specific to the intervention.

Overall, findings of this study revealed that numerous BCTs and MI content and relational techniques were present across the sampled sessions. More specifically, BCTs pertaining to social support and planning predominated, whereas MI relational techniques such as OARS skills were frequently reported. This study provides the first in-depth exploration of PAC delivery and may lay the foundation for future studies. More research is recommended to advance the current state of knowledge to better guide the implementation of effective PAC interventions. 


\section{Contributions of the Authors}

The contributions of the four authors referenced on the journal article are outlined below.

Jean-Christian Gagnon was involved in the following tasks: conceptualization of the project, preparation for data collection (i.e., recruitment, coder training, pilot tests); data collection (i.e., coding PAC sessions); data entry, data analysis, writing (i.e., producing the initial drafts of all sections, which were reviewed by co-authors and returned to me for revisions).

Dr. Michelle Fortier supervised all of the phases of the research and was particularly involved in the following tasks: conceptualization of the project and writing (i.e., multiple rounds of revisions on the journal article and the present thesis).

Taylor McFadden was involved in the following tasks: writing (i.e., multiple rounds of revisions on the journal article)

Yannick Plante was involved in the following tasks: preparation for data collection (i.e., coder training, pilot tests), data collection (i.e., coding of PAC sessions). Yannick also revised the journal article once and provided feedback. 


\section{References}

Abraham, C., \& Michie, S. (2008). A taxonomy of behavior change techniques used in interventions. Health Psychology, 27(3), 379-387. doi:10.1037/02786133.27.3.379

Armstrong, M. J., Mottershead, T. A., Ronksley, P. E., Sigal, R. J., Campbell, T. S., \& Hemmelgarn, B. R. (2011). Motivational interviewing to improve weight loss in overweight and/or obese patients: A systematic review and meta-analysis of randomized controlled trials. Obesity Reviews, 12(9), 709-723. doi:10.1111/j.1467789X.2011.00892.x

Avery, L., Flynn, D., Van Wersch, A., Sniehotta, F. F., \& Trenell, M. I. (2012). Changing physical activity behavior in type 2 diabetes. Diabetes Care, 35(12), 2681-2689. doi:10.2337/dc11-2452

Bélanger-Gravel, A., Godin, G., \& Amireault, S. (2013). A meta-analytic review of the effect of implementation intentions on physical activity. Health Psychology Review, 7(1), 23-54. doi:10.1080/17437199.2011.560095

Bock, C., Diehm, C., \& Schneider, S. (2012). Physical activity promotion in primary health care: results from a German physician survey. The European Journal of General Practice, 18(2), 86-91. doi:10.3109/13814788.2012.675504

Borrelli, B. (2011). The assessment, monitoring, and enhancement of treatment fidelity in public health clinical trials. Journal of Public Health Dentistry, 71(1), 52-63.

doi:10.1111/j.1752-7325.2011.00233.x 
Bouchard, D. R., Baillargeon, J. P., Gagnon, C., Brown, C., \& Langlois, M. F. (2012). Impact of health professionals' contact frequency on response to a lifestyle intervention with individuals at high risk for diabetes. Diabetes Research and Clinical Practice, 96(2), 129-134. doi:10.1016/j.diabres.2011.12.019

Byrt, T., Bishop, J., \& Carlin, J. B. (1993). Bias, prevalence and kappa. Journal of Clinical Epidemiology, 46(5), 423-429.

Carraro, N., \& Gaudreau, P. (2013). Spontaneous and experimentally induced action planning and coping planning for physical activity: A meta-analysis. Psychology of Sport and Exercise, 14(2), 228-248. doi:10.1016/j.psychsport.2012.10.004

Carver, C. S., \& Scheier, M. F. (1982). Control theory: A useful conceptual framework for personality - social, clinical, and health psychology. Psychological Bulletin, 92, 111135. doi:10.1037/0033-2909.92.1.111

Chan, A. W., Tetzlaff, J. M., Gøtzsche, P. C., Altman, D. G., Mann, H., Berlin, J. A., ... Moher, D. (2013). SPIRIT 2013 explanation and elaboration: guidance for protocols of clinical trials. BMJ (Clinical Research Ed.), 346, 7586. doi:10.1136/bmj.e7586

Chatzisarantis, N. L., \& Hagger, M. S. (2007). Mindfulness and the intention-behavior relationship within the theory of planned behavior. Personality and Social Psychology Bulletin, 33(5), 663-676. doi:10.1177/0146167206297401

Colley, R. C., Garriguet, D., Janssen, I., Craig, C. L., Clarke, J., \& Tremblay, M. S. (2011). Physical activity of Canadian adults: Accelerometer results from the 2007 to 2009 Canadian Health Measures Survey. Health Reports, 22(1), 7-14. doi:10.1016/j.yspm.2011.03.006 
Conn, V. S., Hafdahl, A. R., Brown, S. A., \& Brown, L. M. (2008). Meta-analysis of patient education interventions to increase physical activity among chronically ill adults. Patient Education and Counseling, 70(2), 157-172. doi:10.1016/j.pec.2007.10.004

Conn, V. S., Hafdahl, A. R., Moore, S. M., Nielsen, P. J., \& Brown, L. M. (2009). Meta-analysis of interventions to increase physical activity among cardiac subjects. International Journal of Cardiology, 133(3), 307-320. doi:10.1016/j.ijcard.2008.03.052

Cradock, K. A., ÓLaighin, G., Finucane, F. M., Gainforth, H. L., Quinlan, L. R., \& Ginis, K. A. M. (2017). Behaviour change techniques targeting both diet and physical activity in type 2 diabetes: A systematic review and meta-analysis. International Journal of Behavioral Nutrition and Physical Activity, 14(1), 18. doi:10.1186/s12966-016-0436-0

Craig, P., Dieppe, P., Macintyre, S., Michie, S., Nazareth, I., \& Petticrew, M. (2008). Developing and evaluating complex interventions: The new Medical Research Council guidance. BMJ, 337. doi:10.1136/bmj.a16557

Crits-Christoph, P., Gibbons, M. B. C., Hamilton, J., Ring-Kurtz, S., \& Gallop, R. (2011). The dependability of alliance assessments: The alliance-outcome correlation is larger than you might think. Journal of Consulting and Clinical Psychology, 79(3), 267-278. doi:10.1037/a0023668

Deci, E. L., \& Ryan, R. M. (1985). The general causality orientations scale: Self-determination in personality. Journal of Research in Personality, 19(2), 109-134. doi:10.1016/00926566(85)90023-6

Deci, E. L., \& Ryan, R. M. (2010). Self-Determination. In Corsini Encyclopedia of Psychology. doi:10.1002/9780470479216.corpsy0834 
Deci, E. L., \& Ryan, R. M. (2012). Self-determination theory in health care and its relations to motivational interviewing: A few comments. International Journal of Behavioral Nutrition and Physical Activity, 9(1), 24. doi:10.1186/1479-5868-9-24

Department of Health and Human Services. (2014). Healthy People 2020. U.S. Department of Health and Human Services. Washington, D.C.: U.S Dept. of Health and Human Services. Retrieved at: https://www.healthypeople.gov/2020/topicsobjectives/topic/physical-activity/objectives

Direito, A., Dale, L. P., Shields, E., Dobson, R., Whittaker, R., \& Maddison, R. (2014). Do physical activity and dietary smartphone applications incorporate evidence-based behaviour change techniques? BMC Public Health, 14(1), 646. doi:10.1186/1471-2458$14-646$

Dobber, J., van Meijel, B., Barkhof, E., op Reimer, W. S., Latour, C., Peters, R., \& Linszen, D. (2015). Selecting an optimal instrument to identify active ingredients of the motivational interviewing process. Journal of Psychosomatic Research, 78(3), 268-276. doi:10.1016/j.jpsychores.2014.10.010

Dombrowski, S. U., Sniehotta, F. F., Avenell, A., Johnston, M., MacLennan, G., \& AraújoSoares, V. (2012). Identifying active ingredients in complex behavioural interventions for obese adults with obesity-related co-morbidities or additional risk factors for comorbidities: A systematic review. Health Psychology Review, 6(1), 7-32. doi:10.1080/17437199.2010.513298

Exercise is Medicine. (2017). Retrieved at: http://www.exerciseismedicine.org/canada/ 
Fortier, M. S., Hogg, W., O’Sullivan, T. L., Blanchard, C., Reid, R. D., \& Sigal, R. D., ... \& Beaulac, J. (2007). The physical activity counselling (PAC) randomized controlled trial: rationale, methods, and interventions. Applied Phsyiology, Nutrition, and Metabolism, 32(6), 1170-1185. doi:10.1139/H07-075

Fortier, M. S., Wiseman, E., Sweet, S. N., O’Sullivan, T. L., Blanchard, C. M., Sigal, R. J., \& Hogg, W. (2011). A moderated mediation of motivation on physical activity in the context of the physical activity counseling randomized control trial. Psychology of Sport and Exercise, 12(2), 71-78. doi:10.1016/j.psychsport.2010.08.001

Fortier, M. S., Hogg, W., O’Sullivan, T. L., Blanchard, C., Sigal, R. J., Reid, R. D., ... \& Culver, D. (2011). Impact of integrating a physical activity counsellor into the primary health care team: physical activity and health outcomes of the Physical Activity Counselling randomized controlled trial. Applied Physiology, Nutrition, and Metabolism, 36(4), 503514. doi:10.1139/h11-040

Gainforth, H. L., Lorencatto, F., Erickson, K., West, R., \& Michie, S. (2016). Characterizing clients' verbal statements in behavioural support interventions: The case of smoking cessation. British Journal of Health Psychology, 21(3), 600-612. doi:10.1111/bjhp.12188

Gao, S., Stone, R. A., Hough, L. J., Haibach, J. P., Marcus, B. H., Ciccolo, J. T., ... \& Sevick, M. A. (2016). Physical activity counseling in overweight and obese primary care patients: Outcomes of the VA-STRIDE randomized controlled trial. Preventive Medicine Reports, 3, 113-120. doi:10.1016/j.pmedr.2015.12.007 
Greaves, C. J., Sheppard, K. E., Abraham, C., Hardeman, W., Roden, M., Evans, P. H., \& Schwarz, P. (2011). Systematic review of reviews of intervention components associated with increased effectiveness in dietary and physical activity interventions. BMC Public Health, 11(1), 119. doi:10.1186/1471-2458-11-119

Hagger, M. S., \& Hardcastle, S. J. (2014). Interpersonal style should be included in taxonomies of behavior change techniques. Frontiers in Psychology, 5, 254. doi:10.3389/fpsyg.2014.00254

Hankonen, N., Sutton, S., Prevost, A. T., Simmons, R. K., Griffin, S. J., Kinmonth, A. L., \& Hardeman, W. (2015). Which behavior change techniques are associated with changes in physical activity, diet and body mass index in people with recently diagnosed diabetes?. Annals of Behavioral Medicine, 49(1), 7-17. doi:10.1007/s12160-014-9624-9

Hardcastle, S. (2014). Identification of the motivational techniques within Motivational Interviewing and relations with behaviour change techniques from the BCTTv1. The European Health Psychologist, 17(3), 115-121.

Hardcastle, S., Taylor, A., Bailey, M., \& Castle, R. (2008). A randomised controlled trial on the effectiveness of a primary health care based counselling intervention on physical activity, diet and CHD risk factors. Patient Education and Counseling, 70(1), 31-39. doi:10.1016/j.pec.2007.09.014

Hardcastle, S. J., Fortier, M., Blake, N., \& Hagger, M. S. (2017). Identifying content-based and relational techniques to change behavior in motivational interviewing. Health Psychology Review, 11(1), 1-16. doi:10.1080/17437199.2016.1190659 
Hébert, E. T., Caughy, M. O., \& Shuval, K. (2012). Primary care providers' perceptions of physical activity counselling in a clinical setting: A systematic review. British Journal of Sports Medicine, 46(9), 625-631. doi:10.1136/bjsports-2011-090734

Hoffmann, T. C., Glasziou, P. P., Boutron, I., Milne, R., Perera, R., Moher, D., ... Michie, S. (2014). Better reporting of interventions: template for intervention description and replication (TIDieR) checklist and guide. $B M J, 348,1687$. doi:10.1136/bmj.g1687

Hoffmann, T. C., Maher, C. G., Briffa, T., Sherrington, C., Bennell, K., Alison, J., ... \& Glasziou, P. P. (2016). Prescribing exercise interventions for patients with chronic conditions. Canadian Medical Association Journal, 188(7), 510-518. doi:10.1503/cmaj.150684

Hollenstein, T. (2007). State space grids: Analyzing dynamics across development. International Journal of Behavioral Development, 31(4), 384-396. doi:10.1177/0165025407077765

Howlett, N., Trivedi, D., Troop, N. A., \& Chater, A. M. (2015). What are the most effective behaviour change techniques to promote physical activity and/or reduce sedentary behaviour in inactive adults? A systematic review protocol. BMJ Open, 5(8). doi:10.1136/bmjopen-2015-008573

Jepson, R. G., Harris, F. M., Platt, S., \& Tannahill, C. (2010). The effectiveness of interventions to change six health behaviours: A review of reviews. BMC Public Health, 10, 538. doi:10.1186/1471-2458-10-538

Kahn, E. B., Ramsey, L. T., Brownson, R. C., Heath, G. W., Howze, E. H., Powell, K. E., ... Rajab, M. W. (2002). The Effectiveness of Interventions to Increase Physical Activity: A Systematic Review. American Journal of Preventive Medicine, 22, 73-107. doi:10.1016/S0749-3797(02)00434-8 
Kanfer, F. H., \& Gaelick-Buys. (1991). Self-management methods. In F. H. Kanfer \& A. P. Goldstein (Eds.), Helping people change: A textbook of methods (pp. 305-360). New York: Pergamon Press.

Koestner, R., Lekes, N., Powers, T. A., \& Chicoine, E. (2002). Attaining personal goals: Selfconcordance plus implementation intentions equals success. Journal of Personality and Social Psychology, 83(1), 231-244. doi:10.1037/0022-3514.83.1.231

Kohl, H. W., Craig, C. L., Lambert, E. V., Inoue, S., Alkandari, J. R., Leetongin, G., ... \& Lancet Physical Activity Series Working Group. (2012). The pandemic of physical inactivity: Global action for public health. The Lancet, 380(9838), 294-305. doi:10.1016/S01406736(12)60898-8

Krueger, H., Turner, D., Krueger, J., \& Ready, A. E. (2014). The economic benefits of risk factor reduction in Canada: tobacco smoking, excess weight and physical inactivity. Canadian Journal of Public Health, 105(1), 69-78.

Kwasnicka, D., Dombrowski, S., White, M., \& Sniehotta, F. (2016). Theoretical explanations for maintenance of behaviour change: A systematic review of behaviour theories. Health Psychology Review, 10(3), 277-293. doi:10.1080/17437199.2016.1151372

Lara, J., Evans, E. H., O’Brien, N., Moynihan, P. J., Meyer, T. D., Adamson, A. J., ... \& Mathers, J. C. (2014). Association of behaviour change techniques with effectiveness of dietary interventions among adults of retirement age: A systematic review and meta-analysis of randomised controlled trials. BMC Medicine, 12(1), 177. doi:10.1186/s12916-014-0177-3

Larkin, L., Gallagher, S., Cramp, F., Brand, C., Fraser, A., \& Kennedy, N. (2015). Behaviour change interventions to promote physical activity in rheumatoid arthritis: A systematic review. Rheumatology International, 35(10), 1631-1640. doi:10.1007/s00296-015-3292-3 
Lee, I. M., Shiroma, E. J., Lobelo, F., Puska, P., Blair, S. N., Katzmarzyk, P. T., \& Lancet Physical Activity Series Working Group. (2012). Effect of physical inactivity on major non-communicable diseases worldwide: An analysis of burden of disease and life expectancy. The Lancet, 380(9838), 219-229. doi:10.1016/S0140-6736(12)61031-9

Lorencatto, F., West, R., Seymour, N., \& Michie, S. (2013). Developing a method for specifying the components of behavior change interventions in practice: the example of smoking cessation. Journal of Consulting and Clinical Psychology, 81(3), 528-44. doi:10.1037/a0032106

Lubans, D. R., Foster, C., \& Biddle, S. J. H. (2008). A review of mediators of behavior in interventions to promote physical activity among children and adolescents. Preventive Medicine, 47(5), 463-470. doi:10.1016/j.ypmed.2008.07.011

Lundahl, B., Moleni, T., Burke, B. L., Butters, R., Tollefson, D., Butler, C., \& Rollnick, S. (2013). Motivational interviewing in medical care settings: A systematic review and meta-analysis of randomized controlled trials. Patient Education and Counseling, 93(2), 157-168. doi:10.1016/j.pec.2013.07.012

Maes, S., \& Karoly, P. (2005). Self-Regulation assessment and intervention in physical health and illness: A review. Applied Psychology, 54(2), 267-299. doi:10.1111/j.14640597.2005.00210.x

Malik, S. H., Blake, H., \& Suggs, L. S. (2014). A systematic review of workplace health promotion interventions for increasing physical activity. British Journal of Health Psychology, 19(1), 149-180. doi:10.1111/bjhp.12052 
Mammen, G., \& Faulkner, G. (2013). Physical activity and the prevention of depression: A systematic review of prospective studies. American Journal of Preventive Medicine, 45(5), 649-657. doi:10.1016/j.amepre.2013.08.001

Mann, T., De Ridder, D., \& Fujita, K. (2013). Self-regulation of health behavior: social psychological approaches to goal setting and goal striving. Health Psychology, 32(5), 487. doi:10.1037/a0028533

Marcus, B. H., Williams, D. M., Dubbert, P. M., Sallis, J. F., King, A. C., Yancey, A. K., ... \& Claytor, R. P. (2006). Physical activity intervention studies. Circulation, 114(24), 27392752. doi:10.1161/CIRCULATIONAHA.106.179683

Markland, D., Ryan, R. M., Tobin, V. J., \& Rollnick, S. (2005). Motivational interviewing and self-determination theory. Journal of Social and Clinical Psychology, 24(6), 811-831. doi:10.1521/jscp.2005.24.6.811

McDermott, M. S., Oliver, M., Iverson, D., \& Sharma, R. (2016). Effective techniques for changing physical activity and healthy eating intentions and behaviour: A systematic review and meta-analysis. British Journal of Health Psychology, 21(4), 827-841. doi:10.1111/bjhp.12199

McFadden, T., Fortier, M., \& Guérin, E. (2017). Investigating the effects of Physical Activity Counselling on depressive symptoms and physical activity in female undergraduate students with depression: A multiple baseline single-subject design. Mental Health and Physical Activity, 12, 25-36. doi:10.1016/j.mhpa.2017.01.002

Michie, S., Abraham, C., Whittington, C., McAteer, J., \& Gupta, S. (2009). Effective techniques in healthy eating and physical activity interventions: A meta-regression. Health Psychology, 28(6), 690-701. doi:10.1037/a0016136 
Michie, S., Fixsen, D., Grimshaw, J. M., \& Eccles, M. P. (2009). Specifying and reporting complex behaviour change interventions: the need for a scientific method. Implementation Science, 4(1), 40. doi:10.1186/1748-5908-4-40

Michie, S., Ashford, S., Sniehotta, F. F., Dombrowski, S. U., Bishop, A., \& French, D. P. (2011). A refined taxonomy of behaviour change techniques to help people change their physical activity and healthy eating behaviours: The CALO-RE taxonomy. Psychology \& Health, 26(11), 1479-1498. doi:10.1080/08870446.2010.540664

Michie, S., Hyder, N., Walia, A., \& West, R. (2011). Development of a taxonomy of behaviour change techniques used in individual behavioural support for smoking cessation. Addictive Behaviors, 36(4), 315-319. doi:10.1016/j.addbeh.2010.11.016

Michie, S., van Stralen, M. M., \& West, R. (2011). The behaviour change wheel: a new method for characterising and designing behaviour change interventions. Implementation Science, 6(1), 42. doi:10.1186/1748-5908-6-42

Michie, S., Richardson, M., Johnston, M., Abraham, C., Francis, J., Hardeman, W., ... \& Wood, C. E. (2013). The behavior change technique taxonomy (v1) of 93 hierarchically clustered techniques: building an international consensus for the reporting of behavior change interventions. Annals of Behavioral Medicine, 46(1), 81-95. doi:10.1007/s12160013-9486-6

Miller, W. R., \& Rollnick, S. (2012). Meeting in the middle: Motivational interviewing and selfdetermination theory. International Journal of Behavioral Nutrition and Physical Activity, 9(1), 25. doi:10.1186/1479-5868-9-25

Miller, W. R., \& Rollnick, S. (2002). Motivational Interviewing: Preparing people for change. New York. NY: Guilford. 
Miller, W. R., \& Rollnick, S. (2013). Motivational Interviewing: Helping people change. New York. NY: Guilford.

Miller, W. R., \& Rose, G. S. (2009). Toward a theory of motivational interviewing. American Psychologist, 64(6), 527. doi:10.1037/a0016830

Mischel, W., Cantor, N., \& Feldman, S. (1996). Principles of self-regulation: The nature of willpower and self-control. In E. T. Higgins \& A. W. Kruglanski (Eds.), Social Psychology: Handbook of basic principles (pp. 329-360). New York: Guilford Press.

Moore, C., Lee, J., Milligan, J., \& Giangregorio, L. (2015). Physical activity as medicine among family health teams: an environmental scan of physical activity services in an interdisciplinary primary care setting. Applied Physiology, Nutrition, and Metabolism, 40(3), 302-305. doi:10.1139/apnm-2014-0387

Moyers, T. B., Miller, W. R., \& Hendrickson, S. M. L. (2005). How does motivational interviewing work? Therapist interpersonal skill predicts client involvement within motivational interviewing sessions. Journal of Consulting and Clinical Psychology, 73(4), 590-598. doi:10.1037/0022-006X.73.4.590

Muennig, P., \& Bounthavong, M. (2016). Cost-effectiveness analysis in health: a practical approach. John Wiley \& Sons.

Naci, H., \& Ioannidis, J. P. (2013). Comparative effectiveness of exercise and drug interventions on mortality outcomes: metaepidemiological study. British Medical Journal, 347. doi:10.1136/bmj.f5577

National Institute for Health and Care Excellence. (2013). Physical activity: brief advice for adults in primary care. Retrieved at: https://www.nice.org.uk/guidance/PH44/chapter/1Recommendations. 
Ogden, J. (2016). Celebrating variability and a call to limit systematisation: the example of the Behaviour Change Technique Taxonomy and the Behaviour Change Wheel. Health Psychology Review, 10(3), 245-250. doi:10.1080/17437199.2016.1190291

O’Halloran, P. D., Blackstock, F., Shields, N., Holland, A., Iles, R., Kingsley, M., ... Taylor, N. F. (2014). Motivational interviewing to increase physical activity in people with chronic health conditions: A systematic review and meta-analysis. Clinical Rehabilitation, 28(12), 1159-1171. doi:10.1177/0269215514536210

Olander, E. K., Fletcher, H., Williams, S., Atkinson, L., Turner, A., \& French, D. P. (2013). What are the most effective techniques in changing obese individuals' physical activity self-efficacy and behaviour: a systematic review and meta-analysis. International Journal of Behavioral Nutrition and Physical Activity, 10(1), 29. doi:10.1186/1479-5868-10-29

Owen, K. B., Smith, J., Lubans, D. R., Ng, J. Y., \& Lonsdale, C. (2014). Self-determined motivation and physical activity in children and adolescents: A systematic review and meta-analysis. Preventive Medicine, 67, 270-279. doi:10.1016/j.ypmed.2014.07.033

Parker, A. G., Hetrick, S. E., Jorm, A. F., Mackinnon, A. J., McGorry, P. D., Yung, A. R., ...Purcell, R. (2016). The effectiveness of simple psychological and physical activity interventions for high prevalence mental health problems in young people: A factorial randomised controlled trial. Journal of Affective Disorders, 196, 200-209. doi:10.1016/j.jad.2016.02.043

Patel, A., Schofield, G. M., Kolt, G. S., \& Keogh, J. W. (2011). General practitioners' views and experiences of counselling for physical activity through the New Zealand Green Prescription program. BMC Family Practice, 12(1), 119. doi:10.1186/1471-2296-12-119 
Pelletier, L. G., Dion, S. C., Slovinec-D'Angelo, M., \& Reid, R. (2004). Why do you regulate what you eat? Relationships between forms of regulation, eating behaviors, sustained dietary behavior change, and psychological adjustment. Motivation and Emotion, 28(3), 245-277. doi:10.1023/B:MOEM.0000040154.40922.14

Petrella, R. J., Lattanzio, C. N., \& Overend, T. J. (2007). Physical activity counseling and prescription among Canadian primary care physicians. Archives of Internal Medicine, 167(16), 1774-1781. doi:10.1001/archinte.167.16.1774

Presseau, J., Ivers, N. M., Newham, J. J., Knittle, K., Danko, K. J., \& Grimshaw, J. M. (2015). Using a behaviour change techniques taxonomy to identify active ingredients within trials of implementation interventions for diabetes care. Implementation Science, 10(1), 55. doi:10.1186/s13012-015-0248-7

Prince, S. A., Saunders, T. J., Gresty, K., \& Reid, R. D. (2014). A comparison of the effectiveness of physical activity and sedentary behaviour interventions in reducing sedentary time in adults: a systematic review and meta-analysis of controlled trials. Obesity Reviews, 15(11), 905-919. doi:10.1111/obr.12215

Resnicow, K., \& McMaster, F. (2012). Motivational interviewing: Moving from why to how with autonomy support. International Journal of Behavioural Nutrition and Physical Activity, 9(1), 19. doi:10.1186/1479-5868-9-19

Rhodes, R. E., \& Bruijn, G. J. (2013). How big is the physical activity intention-behaviour gap? A met-analysis using the action control framework. British Journal of Health Psychology, 18(2), 296-309. doi:10.1111/bjhp.12032 
Rhodes, R. E., \& Pfaeffli, L. A. (2010). Mediators of physical activity behaviour change among adult non-clinical populations: a review update. International Journal of Behavioral Nutrition and Physical Activity, 7(1), 37. doi:10.1186/1479-5868-7-37

Ritterband, L. M., Thorndike, F. P., Cox, D. J., Kovatchev, B. P., \& Gonder-Frederick, L. A. (2009). A behavior change model for internet interventions. Annals of Behavioral Medicine, 38(1), 18. doi:10.1007/s12160-009-9133-4

Rubak, S., Sandbaek, A., Lauritzen, T., \& Christensen, B. (2005). Motivational interviewing: a systematic review and meta-analysis. The British Journal of General Practice: The Journal of the Royal College of General Practitioners, 55(513), 305-312. doi:10.1037//0278-6133.21.5.444

Ryan, R. M., \& Deci, E. L. (2000). Self-determination theory and the facilitation of intrinsic motivation, social development, and well-being. American Psychologist, 55(1), 68-78. doi:0.1037//0003-066X.55.1.68

Samdal, G. B., Eide, G. E., Barth, T., Williams, G., \& Meland, E. (2017). Effective behaviour change techniques for physical activity and healthy eating in overweight and obese adults; systematic review and meta-regression analyses. International Journal of Behavioral Nutrition and Physical Activity, 14(1), 42. doi:10.1186/s12966-017-0494-y

Schuch, F., Vancampfort, D., Richards, J., Rosenbaum, S., Ward, P. B., \& Stubbs, B. (2016). Exercise as a treatment for depression: A meta-analysis adjusting for publication bias. Journal of Psychiatric Research, 77, 42-51. doi:10.1016/j.psychires.2016.02.023 
Schulz, K. F., Altman, D. G., Moher, D., \& Group, C. (2010). Academia and Clinic Annals of Internal Medicine CONSORT 2010 Statement: Updated Guidelines for Reporting Parallel Group Randomized Trials OF TO. Annals of Internal Medicine, 152(11), $727-$ 732. doi:10.7326/0003-4819-152-11-201006010-00232

Smith, D. M., Taylor, W., \& Lavender, T. (2016). Behaviour change techniques to change the postnatal eating and physical activity behaviours of women who are obese: A qualitative study. BJOG: An International Journal of Obstetrics \& Gynaecology, 123(2), 279-284. doi:10.1111/1471-0528.13751

Sniehotta, F. F., Scholz, U., \& Schwarzer, R. (2005). Bridging the intention-behaviour gap: Planning, self-efficacy, and action control in the adoption and maintenance of physical exercise. Psychology and Health, 20, 143-160. doi:10.1080/08870440512331317670

Stanton, R., Happell, B., Hayman, M., \& Reaburn, P. (2014). Exercise interventions for the treatment of affective disorders- research to practice. Frontiers in Psychiatry, 5, 46. doi: 10.3389/fpsyt.2014.00046

Taylor, N., Conner, M., \& Lawton, R. (2012). The impact of theory on the effectiveness of worksite physical activity interventions: a meta-analysis and meta-regression. Health Psychology Review, 6(1), 33-73. doi:10.1080/17437199.2010.533441

Teixeira, P. J. (2016). Health behavior change: a field just picking up speed. A comment on Ogden (2016). Health Psychology Review, 10(3), 269-273.

doi:10.1080/17437199.2016.1183507 
Teixeira, P. J., Carraça, E. V., Markland, D., Silva, M. N., \& Ryan, R. M. (2012). Exercise, physical activity, and self-determination theory: A systematic review. International Journal of Behavioral Nutrition and Physical Activity, 9(1), 78. doi:10.1186/1479-58689-78

Teixeira, P., \& Hagger, M. (2016). Motivation and behaviour change techniques based on selfdetermination theory: a consensus analysis. European Health Psychologist, 18(S), 389.

Teixeira, P. J., Palmeira, A. L., \& Vansteenkiste, M. (2012). The role of self-determination theory and motivational interviewing in behavioral nutrition, physical activity, and health: An introduction to the IJBNPA special series. International Journal of Behavioral Nutrition and Physical Activity, 9(1), 17. doi:10.1186/1479-5868-9-17

Tremblay, M. S., Warburton, D. E. R., Janssen, I., Paterson, D. H., Latimer, A. E., Rhodes, R. E., ... Duggan, M. (2011). New Canadian Physical Activity Guidelines. Applied Physiology, Nutrition, and Metabolism, 36(1), 36-46. doi:10.1139/H11-009

Trost, S. G., Owen, N., Bauman, A. E., Sallis, J. F., \& Brown, W. (2002). Correlates of adults' participation in physical activity: Review and update. Medicine and Science in Sports and Exercise, 34(12), 1996-2001. doi:10.1249/01.MSS.0000038974.76900.92

Vanbuskirk, K. A., \& Wetherell, J. L. (2014). Motivational interviewing with primary care populations: A systematic review and meta-analysis. Journal of Behavioral Medicine, 37(4), 768-780. doi:10.1007/s10865-013-9527-4

Webb, T. L., Joseph, J., Yardley, L., \& Michie, S. (2010). Using the internet to promote health behavior change: a systematic review and meta-analysis of the impact of theoretical basis, use of behavior change techniques, and mode of delivery on efficacy. Journal of Medical Internet Research, 12(1). doi:10.2196/jmir.1376 
WHO. (2009). Global health risks: Mortality and Burden of Disease Attributable to Selected Major Risks.

Williams, S. L., \& French, D. P. (2011). What are the most effective intervention techniques for changing physical activity self-efficacy and physical activity behaviour - and are they the same? Health Education Research, 26(2), 308-322. doi:10.1093/her/cyr005

Wood, C. E., Richardson, M., Johnston, M., Abraham, C., Francis, J., Hardeman, W., \& Michie, S. (2015). Applying the behaviour change technique (BCT) taxonomy v1: A study of coder training. Translational Behavioral Medicine, 5(2), 134-148.

doi:10.1007/s13142-014-0290-z

Zimmerman, B. J. (1989). A social cognitive view of self-regulated academic learning. Journal of Educational Psychology, 81, 32-339.

Zimmerman, B. J. (2006). Development and adaptation of expertise: The role of selfregulatory processes and beliefs. In The Cambridge Handbook of Expertise and Expert Performance, p. 705-722. Cambridge University Press: New York.

Zimmerman, B. J., \& Campillo, M. (2003). Motivating self-regulated problem solvers. In J. E. Davidson \& R. J. Sternberg (Eds.), The nature of problem solving, p. 233-262. New York: Cambridge University Press. 


\section{APPENDICES \\ Appendix A - Definitions of Common Behaviour Change Techniques (BCTs)}

From Michie et al. (2013)

\begin{tabular}{|c|c|c|c|}
\hline No. & Label & Definition & Example \\
\hline \multicolumn{4}{|c|}{ 1. Goals and planning } \\
\hline 1.1 & Goal setting (behavior) & $\begin{array}{l}\text { Set or agree on a goal defined in terms of the } \\
\text { behavior to be achieved. Note: only code } \\
\text { goal-setting if there is sufficient evidence that } \\
\text { goal set as part of intervention; if goal } \\
\text { unspecified or a behavioral outcome, code } \\
1.3 \text {, Goal setting (outcome); if the goal } \\
\text { defines a specific context, frequency, duration } \\
\text { or intensity for the behavior, also code } 1.4 \text {, } \\
\text { Action planning. }\end{array}$ & $\begin{array}{l}\text { Agree on a daily walking goal (e.g., } 3 \text { miles) } \\
\text { with the person and reach agreement about the } \\
\text { goal. } \\
\text { Set the goal of eating } 5 \text { pieces of fruit per day as } \\
\text { specified in public health guidelines. }\end{array}$ \\
\hline 1.2 & Problem solving & $\begin{array}{l}\text { Analyse, or prompt the person to analyse, } \\
\text { factors influencing the behavior and generate } \\
\text { or select strategies that include overcoming } \\
\text { barriers and/or increasing facilitators } \\
\text { (includes 'Relapse Prevention' and 'Coping } \\
\text { Planning'). } \\
\text { Note: barrier identification without solutions } \\
\text { is not sufficient. If the BCT does not include } \\
\text { analyzing the behavioral problem, consider } \\
12.3 \text {, Avoidance/changing exposure to } \\
\text { cues for the behavior, 12.1, Restructuring } \\
\text { the physical environment, } 12.2 \text {, Restructuring } \\
\text { the social environment, or } 11.2, \text { Reduce } \\
\text { negative emotions. }\end{array}$ & $\begin{array}{l}\text { Identify specific triggers (e.g., being in a pub, } \\
\text { feeling anxious) that generate the urge/want/need } \\
\text { to drink and develop strategies for avoiding } \\
\text { environmental triggers or for managing negative } \\
\text { emotions, such as anxiety, that motivate } \\
\text { drinking. } \\
\text { Prompt the patient to identify barriers preventing } \\
\text { them from starting a new exercise regime e.g., } \\
\text { lack of motivation, and discuss ways in which } \\
\text { they could help overcome them e.g., going to the } \\
\text { gym with a buddy. }\end{array}$ \\
\hline 1.4 & Action planning & $\begin{array}{l}\text { Prompt detailed planning of performance of } \\
\text { the behavior (must include at least one of }\end{array}$ & $\begin{array}{l}\text { Encourage a plan to carry condoms when going } \\
\text { Out socially at weekends. }\end{array}$ \\
\hline
\end{tabular}




\begin{tabular}{|c|c|c|c|}
\hline & & $\begin{array}{l}\text { context, frequency, duration and intensity). } \\
\text { Context may be environmental (physical } \\
\text { or social) or internal (physical, emotional } \\
\text { or cognitive) (includes 'Implementation } \\
\text { Intentions'). } \\
\text { Note: evidence of action planning does not } \\
\text { necessarily imply goal setting, only code } \\
\text { latter if sufficient evidence }\end{array}$ & $\begin{array}{l}\text { Prompt planning the performance of a particular } \\
\text { physical activity (e.g., running) at a particular } \\
\text { time (e.g., before work) on certain days of the } \\
\text { week. }\end{array}$ \\
\hline \multicolumn{4}{|c|}{ 2. Feedback and monitoring } \\
\hline 2.3 & $\begin{array}{l}\text { Self-monitoring of } \\
\text { behavior }\end{array}$ & $\begin{array}{l}\text { Establish a method for the person to monitor } \\
\text { and record their behavior(s) as part of a } \\
\text { behavior change strategy. } \\
\text { Note: if monitoring is part of a data collection } \\
\text { procedure rather than a strategy aimed at } \\
\text { changing behavior, do not code; if monitoring } \\
\text { of outcome of behavior, code } \\
2.4, \text { Self-monitoring of outcome(s) of } \\
\text { behavior; if monitoring is by someone else } \\
\text { (without feedback), code } 2.1 \text {, Monitoring } \\
\text { of behavior by others without feedback. }\end{array}$ & $\begin{array}{l}\text { Ask the person to record daily, in a diary, } \\
\text { whether they have brushed their teeth for at least } \\
\text { two minutes before going to bed } \\
\text { Give patient a pedometer and a form for } \\
\text { recording daily total number of steps }\end{array}$ \\
\hline \multicolumn{4}{|c|}{ 3. Social support } \\
\hline 3.1 & $\begin{array}{l}\text { Social support } \\
\text { (unspecified) }\end{array}$ & $\begin{array}{l}\text { Advise on, arrange or provide social support } \\
\text { (e.g., from friends, relatives, colleagues,' } \\
\text { buddies' or staff) or non-contingent praise } \\
\text { or reward for performance of the behavior. It } \\
\text { includes encouragement and counselling, but } \\
\text { only when it is directed at the behavior } \\
\text { Note: attending a group class and/or mention } \\
\text { of 'follow-up' does not necessarily } \\
\text { apply this BCT, support must be explicitly } \\
\text { mentioned; if practical, code 3.2, Social } \\
\text { support (practical); if emotional, code } 3.3 \text {, } \\
\text { Social support (emotional) (includes }\end{array}$ & $\begin{array}{l}\text { Advise the person to call a 'buddy' when they } \\
\text { experience an urge to smoke. } \\
\text { Arrange for a housemate to encourage } \\
\text { continuation with the behavior change } \\
\text { programme. } \\
\text { Give information about a self-help group that } \\
\text { offers support for the behavior. }\end{array}$ \\
\hline
\end{tabular}




\begin{tabular}{|c|c|c|c|}
\hline & & $\begin{array}{l}\text { 'Motivational interviewing' and 'Cognitive } \\
\text { Behavioral Therapy'). }\end{array}$ & \\
\hline \multicolumn{4}{|c|}{ 5. Natural consequences } \\
\hline 5.1 & $\begin{array}{l}\text { Information about health } \\
\text { consequences }\end{array}$ & $\begin{array}{l}\text { Provide information (e.g., written, verbal, } \\
\text { visual) about health consequences of } \\
\text { performing the behavior. } \\
\text { Note: consequences can be for any target, not } \\
\text { just the recipient(s) of the intervention; } \\
\text { emphasizing importance of consequences } \\
\text { is not sufficient; if information about } \\
\text { emotional consequences, code 5.6, } \\
\text { Information about emotional consequences; } \\
\text { if about social, environmental or unspecified } \\
\text { consequences code 5.3, Information about } \\
\text { social and environmental consequences. }\end{array}$ & $\begin{array}{l}\text { Explain that not finishing a course of antibiotics } \\
\text { can increase susceptibility to future infection. } \\
\text { present the likelihood of contracting a sexually } \\
\text { transmitted infection following unprotected } \\
\text { sexual behavior. }\end{array}$ \\
\hline \multicolumn{4}{|c|}{ 7. Associations } \\
\hline 7.1 & Prompts/cues & $\begin{array}{l}\text { Introduce or define environmental or social } \\
\text { stimulus with the purpose of prompting or } \\
\text { cueing the behavior. The prompt or cue would } \\
\text { normally occur at the time or place of } \\
\text { performance. } \\
\text { Note: when a stimulus is linked to a specific } \\
\text { action in an if-then plan including one or } \\
\text { more of frequency, duration or intensity also } \\
\text { code } 1.4 \text {, Action planning. }\end{array}$ & $\begin{array}{l}\text { Put a sticker on the bathroom mirror to remind } \\
\text { people to brush their teeth. }\end{array}$ \\
\hline \multicolumn{4}{|c|}{ 8. Repetition and substitution } \\
\hline 8.1 & $\begin{array}{l}\text { Behavioral } \\
\text { practice/rehearsal }\end{array}$ & $\begin{array}{l}\text { Prompt practice or rehearsal of the } \\
\text { performance of the behavior one or more } \\
\text { times in a context or at a time when the } \\
\text { performance may not be necessary, in order } \\
\text { to increase habit and skill. } \\
\text { Note: if aiming to associate performance with } \\
\text { the context, also code } 8.3 \text {, Habit formation. }\end{array}$ & $\begin{array}{l}\text { Prompt asthma patients to practice measuring } \\
\text { their peak flow in the nurse's consulting room. }\end{array}$ \\
\hline
\end{tabular}




\begin{tabular}{|c|c|c|c|}
\hline \multicolumn{4}{|c|}{ 9. Comparison of outcomes } \\
\hline 9.2 & Pros and cons & $\begin{array}{l}\text { Advise the person to identify and compare } \\
\text { reasons for wanting (pros) and not wanting to } \\
\text { (cons) change the behavior (includes } \\
\text { 'Decisional balance'). } \\
\text { Note: if providing information about health } \\
\text { consequences, also code 5.1, Information } \\
\text { about health consequences; if providing } \\
\text { information about emotional consequences, } \\
\text { also code 5.6, Information about emotional } \\
\text { consequences; if providing information about } \\
\text { social, environmental or unspecified } \\
\text { consequences also code 5.3, Information } \\
\text { about social and environmental consequences. }\end{array}$ & $\begin{array}{l}\text { Advise the person to list and compare the } \\
\text { advantages and disadvantages of prescribing } \\
\text { antibiotics for upper respiratory tract infections. }\end{array}$ \\
\hline \multicolumn{4}{|c|}{ 15. Self-belief } \\
\hline 15.4 & Self talk & $\begin{array}{l}\text { Prompt positive self-talk (aloud or silently) } \\
\text { before and during the behavior. }\end{array}$ & $\begin{array}{l}\text { Prompt the person to tell themselves that a walk } \\
\text { will be energizing. }\end{array}$ \\
\hline
\end{tabular}




\section{Appendix B - Motivational Interviewing Process Stages}

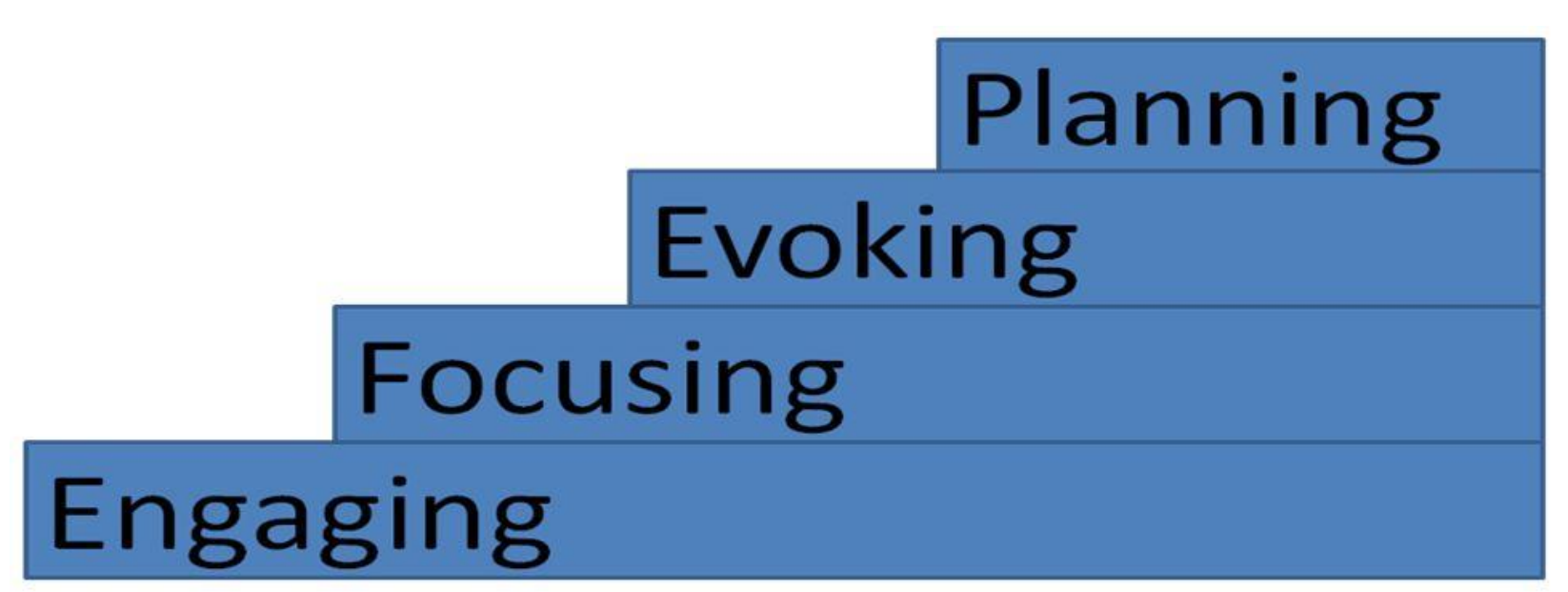

Image retrieved from: http://www.healthyteennetwork.org/blog/supporting-change-through-motivational-interviewing/) 
Appendix C - Distinctiveness and Overlap of MI techniques and BCTs

\section{MI techniques}

\section{BCTs}

38 MI techniques total

$>22$ unique to $\mathrm{MI}$ :

* 14 relational

* 8 content

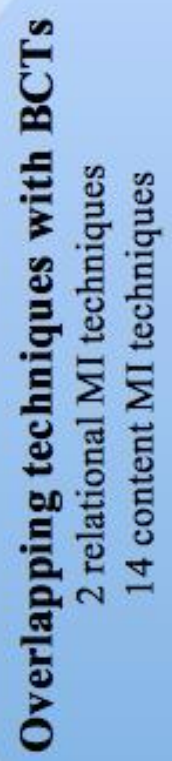

93 BCTs total

$>$ Exclusively 'content' techniques but:

* Social support (unspecified)

* Social support (emotional) 


\section{Appendix D - Table of MI Techniques}

From Hardcastle et al. (2017)

Table 1. Summary of Ml techniques.

\begin{tabular}{|c|c|c|c|c|}
\hline $\begin{array}{l}\text { Technique } \\
\text { number }\end{array}$ & Technique & Definition & Example of technique & $\begin{array}{l}\text { Technique defined } \\
\text { as content or } \\
\text { relational }\end{array}$ \\
\hline
\end{tabular}

1. Openended questions

2. Affirmation

3. Reflective statements

4. Summary statements

Focusing techniques

5. Agenda mapping

6. Review a typical day

7. Permission to provide information and advice 8. Elicit-provide-elicit

Evoking techniques

Running head start

10.

Importance ruler

11.

Confidence ruler
The counsellor asks questions that cannot be answered with a limited response (i.e., yes, no, maybe, twice).

The counsellor provides a statement of affirmation that

acknowledges the client's difficulties, efforts and self-worth.

The counsellor paraphrases client comments by repeating back what the client has said.

What have you tried before to make a change?' and 'How can I Relational help with xxx?'

'I've enjoyed talking with you today'

Relational

Simple reflections: It sounds like you ...' or 'The message I'm Relational getting is that ...'

offers a summary.

The counsellor prompts the client to consider the way ahead and which behaviour they are motivated to discuss.

A prompt from the counsellor to build rapport while collecting information.

The counsellor obtains the permission of the client before providing information or advice.

The counsellor first elicits the client's understanding and need for information, then provides information in a neutral manner, followed by eliciting what this information might mean for the client.

A strategy for eliciting client motivational talk in which the counsellor asks open questions to first explore the perceived 'good things' about the status quo, in order to then query the 'not so good things 'about the status quo.

The counsellor asks open questions, using an importance ruler to 'How important would you say it is for you to xxx?' On a scale of 0- Content explore the client's motivation in terms of how important it is to 10 , where 0 means not at all important and 10 means 'the most make a behaviour change. A scale (typically $0-10$ ) is often used to important thing for me right now', how important would you say ask clients to rate the importance of making a particular change. it is for you to $\mathrm{xxx}^{\prime}$ ' The counsellor asks open questions, using a confidence ruler to
explore the client's motivation in terms of how confident they are

to make a behaviour change. A scale (typically $0-10$ ) is often used

to ask clients to rate their confidence in making a particular change.

usually talk to people in a situation like yours about diet, exercise, Relational that sort of thing. Which of these do you feel you would like to talk about?'

you from beginning to end, and where (behaviour) fits in?

you from beginning to end, and whe harked for other people Relational or what they have found useful?

'ell me what you already know about type II diabetes?' (counsellor Content elicits)

'I'd like to share with you some information about what diabetes is and how it can be most effectively managed. Would that be ok with you?' (counsellor seeks to provide)

'What are the good things about (the status quo)?' 'What are the Content not so good things about (the status quo)?' What are the not so good things about changing (behaviour)?

'Again if 0 stands for not at all confident and 10 stands for very confident, what number would you give yourself and why?

Conten 


\begin{tabular}{|c|c|c|c|c|}
\hline $\begin{array}{l}\text { Technique } \\
\text { number }\end{array}$ & Technique & Definition & Example of technique & $\begin{array}{l}\text { Technique defined } \\
\text { as content or } \\
\text { relational }\end{array}$ \\
\hline 12. & DARN questions & $\begin{array}{l}\text { The counsellor uses DARN questions (open-ended questions) that } \\
\text { seek to elicit four subtypes of client motivational talk. These four } \\
\text { subtypes are: Desire, Ability, Reason and Need. }\end{array}$ & $\begin{array}{l}\text { 'What do you hope our work together will accomplish' (D) 'How } \\
\text { would you do it if you decided to' (A) }\end{array}$ & Content \\
\hline
\end{tabular}

Looking forward

Looking back
Reframing

Hypothetical thinking

\section{Query extremes}

Identify past successes

\section{Identify strengths}

Brainstorming

Troubleshooting

\section{Values exploration} (open or structured)

Double-sided reflection

Emphasise autonomy
The client is prompted to envision two possible futures. The first 'If you were to change what would it be like?' How would you feel? Content 'future' is if they continue on the same path without any changes How would things be different?' where they might be five or ten years from now. The second future is if they decide to make a change, what their future might look like.

The client is prompted by the counsellor to talk about what life was A client may say: I wasn't always this way' and the counsellor may Content like 'before'. The goal is for the client to observe how they have say. 'It sounds like things have changed over time. Tell me about changed over time which may enhance motivation to return to a your eating habits back then'. previous way of being.

The counsellor prompts the client to adopt hypothetical thinking to 'Suppose that you did decide to change (behaviour) how would Content

you go about it?'
A technique used to evoke change talk by asking clients to imagine 'Suppose you did not change, what is the WORST thing that might Content best consequences of change or worst consequences of status happen?' quo.

at behavioural changes to build confidence for change.

The counsellor prompts the client to draw out their strengths and 'What are your key strengths?' the relevance of these strengths to making successful behavioural changes.

The counsellor prompts the client to generate a menu of options. 'What are your ideas about how you could change (behaviour)?' Content The counsellor prompts the client to think about potential barriers 'Suppose that this one big obstacle weren't there. If that obstacle Content

and identify ways of overcoming them in order to strengthen were removed, then how might you go about making this motivation.

The counsellor prompts the client to explore his or her values and 'What things are most important to you?' or 'What do you most Content how the behaviour fits in with these values. The counsellor may want in life?' and 'How do your eating practices fit in with your ask the client to describe their main goals and values in life. For goals and values?' structured values exploration, see Appendix A.

A counsellor reflective statement that invites the client to consider a 'I can't do it' to 'So you find it difficult to ....' more positive and motivational interpretation of what has been said.

The counsellor provides a double-sided reflection to capture client ambivalence and communicate to the client that the counsellor heard their reasons both for and against change. The counsellor provides a statement that directly expresses about changing $x x^{\prime}$ motivational support, acknowledging the client's ability for choice and self-determination. change?'

'On the one hand, you would like to change XX, but on the other Relational

hand changing $X X$ would mean giving up $X X$ ' or 'you are torn
'Do you have any ideas on how we may resolve this dilemma?' Relational
Content

Content

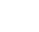


Shifting focus

(CATs)

persistence

support
Overshooting is a motivational technique provided by the counsellor to argue against change by exaggerating the benefits of or minimising the harm associated with a risky behaviour.

A reflective statement, provided by the counsellor that understates
slightly what the client has offered. By slightly understating the expressed intensity of emotion, the client is more likely to continue exploring and telling the counsellor about it.

Coming alongside $\quad$ A counsellor response to persistent resistance talk or discord in
which the counsellor accepts and reflects the client's resistance.

Coming alongside $\quad$ A counsellor response to persistent resistance talk or discord in
which the counsellor accepts and reflects the client's resistance.

A counsellor responds to discord and low level of motivation by pedirecting atter

Agreement with a twist A reflection whereby the counsellor reframes a negative comment by the client into a more positive response.

The counsellor communicates to clients that having difficulties while changing is not uncommon.

The counsellor prompts the client to identify the outcomes that the "Th client expects to achieve based on the changes that they are motivated to make.

expectations

Consider change option

'So you see no benefit in changing XX' or 'XX is all positive for you'. Relational The counsellor, by arguing against change can exhaust the client's negativity.

The client says 'I'm out of breath even walking up the stairs' and Relational the counsellor responds with: 'You're beginning to notice that everyday activities are more difficult'

'Perhaps now is not the right time to be thinking about change?' Relational 'Since you've been forced to come here, what would you like to do Relational with the time we have left together today' I have no will

'Many people report feeling like you do. They want to lose weight, Content but find it difficult'

'Thinking about the benefits of (behaviour) that you've just been Content describing, what kinds of changes to your current level of (behaviour) are you prepared to make?

Content neutral and supportive manner.

Develop a change plan The counsellor prompts the client to develop a specific change plan 'What do you intend to do specifically?'

$\mathrm{C}=$ Commitment

A = Activation

T = Taking steps

Goal attainment scaling A way to specify degrees of change towards the goal and focus motivation using $a-3$ to +3 scale where 0 is the status quo at the outset. The counsellor prompts the client to rate their goals on a scale ranging from the best possible outcome to the worst possible outcome.

\section{Support change/}

Offer emotional

Review outcome goal

The counsellor functions as a part
with the client's own expertise.

The counsellor offers reassurance, to the client.

What would be a good first step?' (A)

When and how will that step be taken?' (T)

Rate a weight loss goal on a scale ranging from -3 (most unfavourable outcome): gain $5 \mathrm{~kg}$ in one month to +3 (most favourable outcome): lose $5 \mathrm{~kg}$ in one month where 0 is the status quo (remain at current weight)

'How can I best support you?'

'I appreciate how difficult this is'

Relational

Relational

Content goals.

Summarise the plan

The counsellor summarises the change plan including the specific "so behavioural goals, the reasons for making the change, the specific steps to be taken, the outcome goals and coping planning for relapse prevention. 


\section{Appendix E - Coding Framework for PAC sessions}

BCTs from BCTTV1

1. Goals and planning

1.1 Goal setting (behavior)

1.2 Problem solving

$1.3 \mathrm{Goal}$ setting (outcome)

1.4 Action planning

1.5 Review behavior goals

1.6 Discrepancy between current behavior and goa

1.7 Review outcome goals

1.8 Behavioral contract

1.9 Commitment

2.1 Monitoring of behavior by others without feedback

2.2 Feedback on behavior

2.3 Self-monitoring of behavior

2.4 Self-monitoring of outcome(s) of behavio

2.5 Monitoring outcome(s) of behavior by others without feedback

2.6 Biofeedback

2.7 Feedback on outcome(s) of behavior

3. Social support

3.1 Social support (unspecified)

3.2 Social support (practical)

3.3 Social support (emotional)

4. Shaping knowledge

4.1 Instruction on how to perform a behavior

4.2 Information about antecedents

4.3 Re-attribution

4.4 Behavioral experiments

5. Natural consequences

5.1 Information about health consequences

5.2 Salience of consequences

5.3 Information about social and environmental consequences

5.4 Monitoring of emotional consequences

5.5 Anticipated regret

5.6 Information about emotional consequences

6. Comparison of behavior

6.1 Demonstration of the behavior
PARTICIPANT 3 (15), PAC 1. LENGTH (seconds): 1656

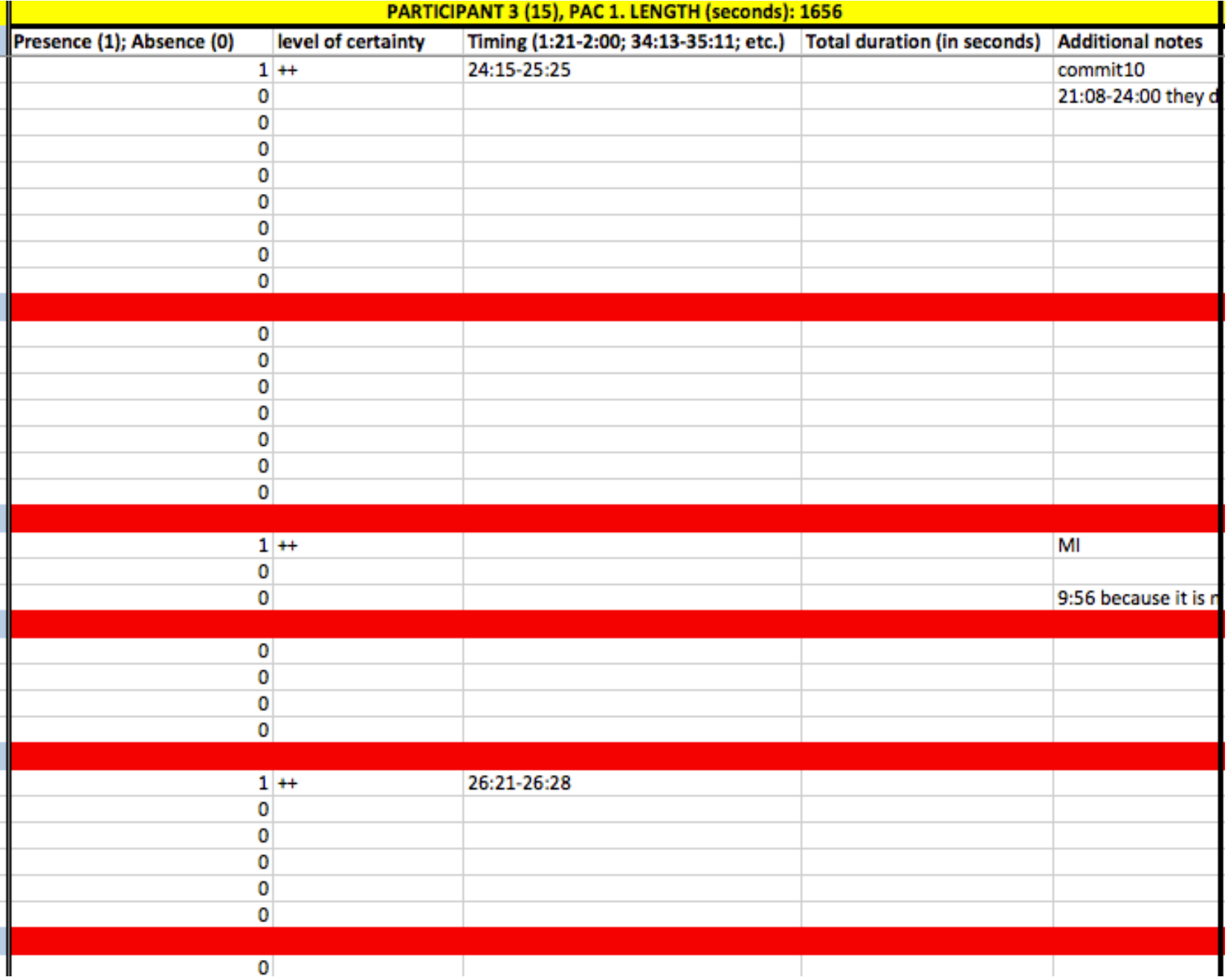




\section{Appendix F - Motivational Interviewing Techniques and Basic Psychological Needs}
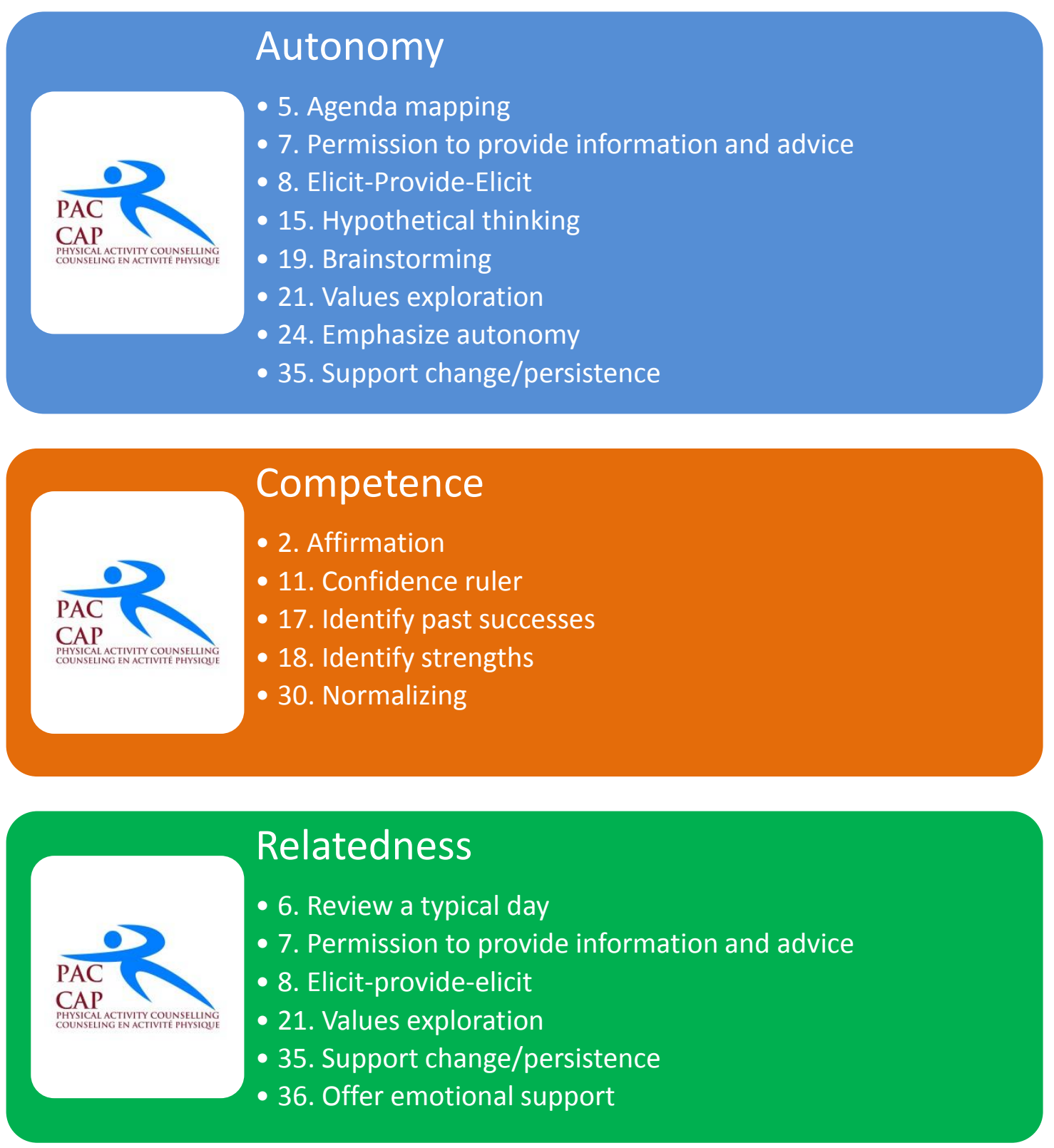